\title{
Simulation of the ozone formation in the northern part of the Po Valley
}

\author{
A. Martilli, ${ }^{1}$ A. Neftel, ${ }^{2}$ G. Favaro, ${ }^{3}$ F. Kirchner, ${ }^{1}$ S. Sillman, ${ }^{4}$ and A. Clappier ${ }^{1}$ \\ Received 21 February 2001; revised 22 August 2001; accepted 31 August 2001; published 15 November 2002.
}

[1] The formation of photooxidants and aerosols in the Milan area (Po Valley, Italy) has been simulated for 13 May 1998 with an Eulerian model. The high-pressure conditions and the weak synoptic circulation favor the formation of strongly enhanced photooxidants and aerosol levels downwind of the metropolitan area of Milan. The polluted air masses are transported northward where the highest ozone $\left(\mathrm{O}_{3}\right)$ concentrations of up to $200 \mathrm{ppb}$ are reached 30 to $40 \mathrm{~km}$ away from the city center of Milan. The core of the Milan plume has an extension of only $10 \mathrm{~km}$ in length and $15 \mathrm{~km}$ in width at $1600 \mathrm{LT}$. The focus of the simulation was the sensitivity of the $\mathrm{O}_{3}$ formation to the reduction of nitrogen oxides $\left(\mathrm{NO}_{x}\right)$ and volatile organic compounds (VOC) emissions. The model results are compared to the measurements in order to evaluate the quality of the simulation. The spatial and temporal variations of the concentrations of $\mathrm{O}_{3}$ and other trace compounds are reasonably well reproduced. Several reasons for systematic deviations have been analyzed in order to understand their possible influence on the sensitivity analysis. Moreover, the simulation showed that indicator species such as the $\mathrm{H}_{2} \mathrm{O}_{2} / \mathrm{HNO}_{3}$ or $\mathrm{O}_{3} / \mathrm{NO}_{y}$ ratio could be applied to characterize the $\mathrm{VOC} / \mathrm{NO}_{x}$ regime of the $\mathrm{O}_{3}$ production in the Milan area, but that it is necessary to modify the indicator ratios to include the aerosol nitrate. Highest $\mathrm{O}_{3}$ values appear at the transition from VOC to $\mathrm{NO}_{x}$ sensitivity approximately $30 \mathrm{~km}$ downwind of the highest emissions. INDEX TERMS: 0345 Atmospheric Composition and Structure: Pollution - urban and regional (0305); 0368 Atmospheric Composition and Structure: Troposphere - constituent transport and chemistry; 0305 Atmospheric Composition and Structure: Aerosols and particles (0345, 4801); 0365 Atmospheric Composition and Structure: Troposphere-composition and chemistry; KEYWORDS: chemical transport models, $\mathrm{VOC} / \mathrm{NO}_{x}$, sensitivity, photooxidants, aerosols, indicators

Citation: Martilli, A., A. Neftel, G. Favaro, F. Kirchner, S. Sillman, and A. Clappier, Simulation of the ozone formation in the northern part of the Po Valley, J. Geophys. Res., 107(D22), 8195, doi:10.1029/2001JD000534, 2002.

\section{Introduction}

[2] A major topic of the European research initiative EUROTRAC-2 is devoted to the development of reduction strategies in order to lower the photochemical ozone $\left(\mathrm{O}_{3}\right)$ levels in Europe. The major policy question in the tropospheric $\mathrm{O}_{3}$ problem is devising proper precursor reduction schemes. This is where Limitation of Oxidants Production (LOOP) sets in. In 1998 the LOOP activity focused on the Pianura Padana Produzione di Ozono (PIPAPO) campaign that took place in May to mid-June in the northern part of the Po Valley. This region offers many interesting aspects with respect to air pollution problems and reduction strategies, including (1) frequent episodes with very high photooxidant levels, (2) recirculation of air masses over the Po

\footnotetext{
${ }^{1}$ Laboratoire de Pollution de l'Air et des Sols, Ecole Polytechnique Federale Lausanne, Lausanne, Switzerland.

${ }^{2}$ Institut für Umwelt und Landwirtschaft (IUL), Liebefeld, Switzerland.

${ }^{3}$ Météo Suisse, Station Aérologique de Payerne, Payerne, Switzerland.

${ }^{4}$ Department of Atmospheric, Oceanic and Space Sciences, University of Michigan, Ann Arbor, Michigan, USA.
}

Copyright 2002 by the American Geophysical Union. 0148-0227/02/2001JD000534
Valley owing to the topographic situation, (3) rapid changeover from volatile organic compound (VOC) to nitrogen oxide $\left(\mathrm{NO}_{x}\right)$ limited $\mathrm{O}_{3}$ production, and (4) large production of secondary aerosol with a major influence from biogenic VOC and $\mathrm{NH}_{3}$ emission due to intensive farming and high emissions of isoprene and terpenes in the pre-Alps.

[3] The $\mathrm{O}_{3}$ production is a nonlinear function of the pollutants $\mathrm{NO}_{x}$ and VOC. The nonlinearity of the $\mathrm{O}_{3}$ formation process with respect to the precursors derives from the fact that a simple causality between emission strength and $\mathrm{O}_{3}$ concentrations does not exist. Two different regimes of the $\mathrm{O}_{3}$ production can be defined. If reduction of $\mathrm{NO}_{x}$ emissions is more effective in reducing the $\mathrm{O}_{3}$ production than reduction of $\mathrm{VOC}$ emissions, the system is $\mathrm{NO}_{x}$ sensitive. In the opposite case the system is VOC sensitive. $\mathrm{O}_{3}$ formation in high $\mathrm{NO}_{x}$ emission density regions, typically urban regions, starts in the VOC-sensitive chemical regime. Downwind of such emission sources, the $\mathrm{O}_{3}$ production will sooner or later become $\mathrm{NO}_{x}$ sensitive. The change-over to $\mathrm{NO}_{x}$-sensitive $\mathrm{O}_{3}$ production depends on the intensity of the chemical reactivity, basically the odd $\mathrm{H}$ radical $\left(\mathrm{OH}, \mathrm{HO}_{2}+\mathrm{RO}_{2}\right)$ concentrations and the dilution of the precursors due to turbulent mixing. Recirculation of already polluted air masses over areas with high emission 


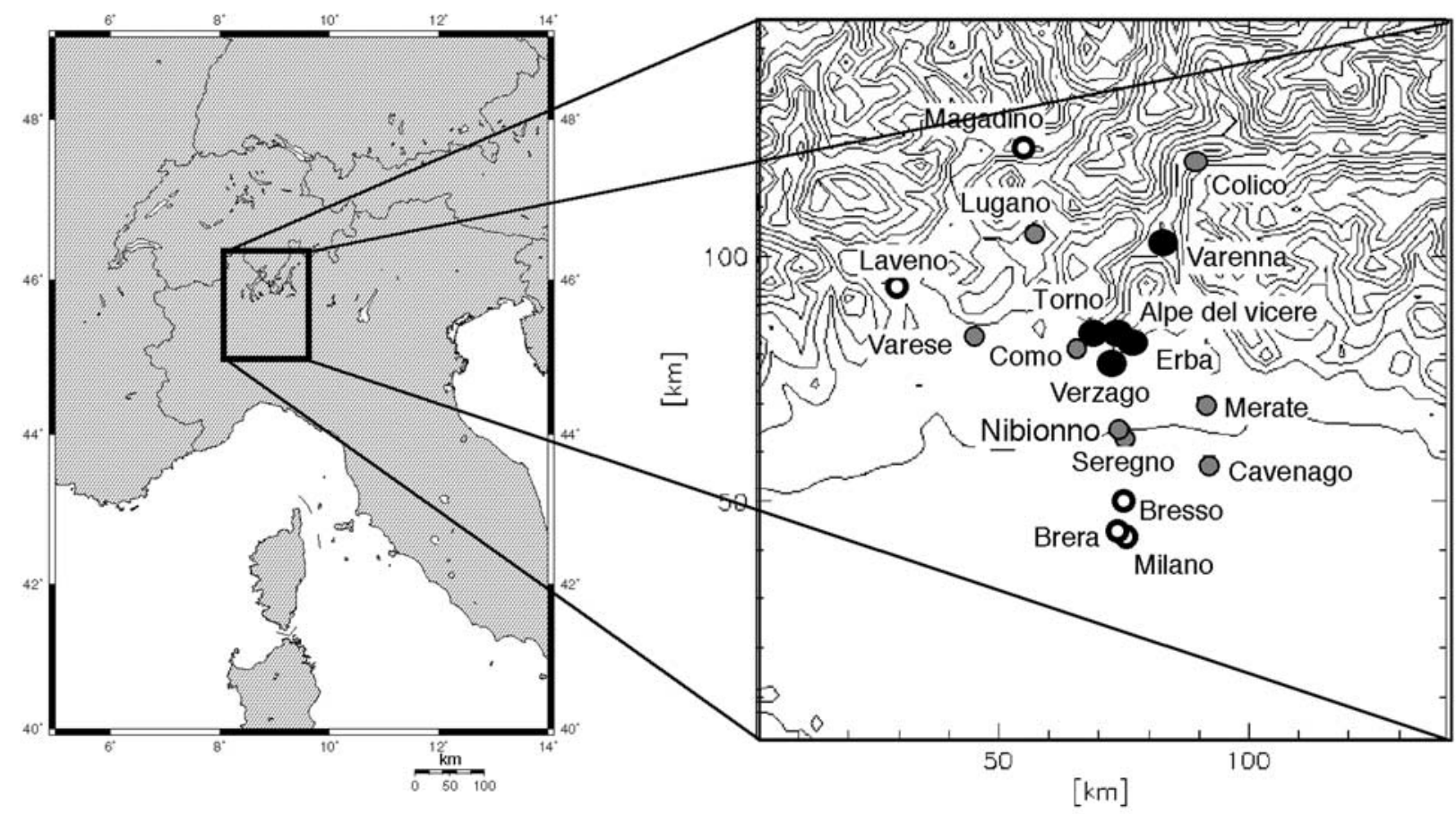

Figure 1. Domain of the Pianura Padana Produzione di Ozono (PIPAPO) experiments. The framed rectangle indicates the extension of the domain used for the numerical simulation. The circles denote the location of different measurement stations (large solid circles for the stations of category 3 , shaded circles for the stations of category 2 , and open circles for the stations of category 1).

density might lead to a back and forth bouncing of the sensitivity of the $\mathrm{O}_{3}$ formation.

[4] In this work the Topographic Vorticity-Mode Mesoscale Model coupled with the Lurmann-Carter-Coyner chemical mechanism (TVM-LCC) simulates the $\mathrm{O}_{3}$ formation in the northern part of the Po Valley. The results are used to investigate the sensitivity of the $\mathrm{O}_{3}$ production to changes in VOC and $\mathrm{NO}_{x}$ emissions, as well as the influence of secondary aerosol formation on the characterization of the $\mathrm{O}_{3}$ sensitivity. The first intensive observation period (IOP) of the PIPAPO experiment was selected as the reference case and is the base for an evaluation of the model performance.

\section{PIPAPO Experiment}

[5] Photochemical pollution in the Po Valley has been investigated in recent years with experimental campaigns and modeling studies. Among these, Silibello et al. [1998] and Finzi et al. [2000] studied the Milan metropolitan area using a diagnostic model to provide meteorological fields for an Eulerian photochemical model. On the other hand, Staffelbach et al. [1997b] adopted a Lagrangian modeling technique to evaluate the impact of Po Valley emissions on air pollution levels in the south of Switzerland. The same topic has been addressed by Grell et al. [2000], by means of a multiscale coupled meteorological-chemical model.

[6] The aim of the PIPAPO campaign is to evaluate both experimentally and numerically the production of $\mathrm{O}_{3}$ and other pollutants between Milan and the Alps. For sunny conditions a heat low over the Alps is formed during the day with a subsequent flow directed from the urban area of
Milan to the Alps. Earlier investigations by Prévôt et al. [1997], Silibello et al. [1998], and Staffelbach et al. [1997a, 1997b] showed that under the condition of low wind speed the likelihood of a Milan $\mathrm{O}_{3}$ plume with concentrations up to $100 \mathrm{ppb}$ is high. A rapid change-over from $\mathrm{VOC}$ to $\mathrm{NO}_{x}$ sensitivity of the $\mathrm{O}_{3}$ concentration has been postulated on the basis of analysis with a one-dimensional (1-D) Lagrangian model. The design of the PIPAPO experiment followed a Lagrangian approach with three ground stations (Bresso, Seregno, and Verzago) in a line of $40 \mathrm{~km}$ length in the northern direction from the border of the city of Milan to the foothills of the Alps (Figure 1). During two IOPs the measurements have been complemented by airplane measurements. In addition, a dense measuring network is operating by local authorities.

[7] The first IOP took place on 12 and 13 May at the end of a long-lasting high-pressure situation over the whole of western Europe. The second IOP was scheduled from 1 June to 8 June. On 13 May a strong $\mathrm{O}_{3}$ plume with concentrations up to 200 ppbv developed $35 \mathrm{~km}$ north of Milan. This day was selected by the PIPAPO model community to serve as surrogate for the sunny summer days leading to high photooxidant levels in the northern part of the Lombardy region.

\section{Model Description}

\subsection{Model Formulation}

[8] The model used in this study is the mesoscalemeteorological model TVM [Bornstein et al., 1996; Schayes et al., 1996; Thunis and Clappier, 2000] coupled to the California Institute of Technology (CIT) [Harley et al., 
1993] chemical module using the LCC chemical reactions [Lurmann et al., 1987].

\subsubsection{Meteorological and Transport Module}

[9] The mesoscale model TVM is nonhydrostatic and anelastic. It forecasts temperature, humidity, wind fields, and turbulence solving prognostic equations for the vorticity, the specific humidity, the potential temperature, and the turbulent kinetic energy [Schayes et al., 1996; Thunis and Clappier, 2000].

[10] The pollutant transport, as well as all the advection terms, is computed by a third-order positive definite mass conservative scheme (PPM) [Collella and Woodward, 1984] corrected for multidimensional applications [Clappier, 1998].

[11] The turbulence transport in the vertical direction is simulated using the $\mathrm{K}$ theory in the vertical direction only. The $\mathrm{K}$ values are deduced from the turbulent kinetic energy and the mixing length using the Therry and Lacarrère [1983] parameterization. The turbulent fluxes at the ground surface are calculated with the analytical functions of Businger et al. [1971]. The same turbulent diffusion coefficients are used for the potential temperature, the specific humidity, the turbulent kinetic energy, and the pollutants.

[12] A feature of the TVM-LCC model is the coupling technique between the meteorological and pollutant modules: The first one calculates wind, temperature, and turbulent fields, and the second one calculates transport and chemical transformations. The two modules run simultaneously but with different time steps. Because of different numerical stability constraints, the meteorological module needs a shorter time step than is required by the pollutant module. Meteorological variables therefore are computed and averaged over $n$ time steps of length $\Delta t_{\text {dyn }}$ (dynamic time step) until the numerical stability condition (CourantFriedrich-Levy (CFL) criterion) is reached for the pollutant transport. The pollutant module is then run for a time step of length $\Delta t_{\text {trp }}=n \Delta t_{\text {dyn }}$ (time step of the transport/chemistry). A series of 2-D tests has shown that this method minimizes transport calculation errors while keeping a low computational time consumption. In this study, $\Delta t_{\text {dyn }}$ is chosen to be $30 \mathrm{~s}$, and $\Delta t_{\text {trp }}$ is computed using the CFL criterion (120 s to $200 \mathrm{~s}$, depending on wind speed).

\subsubsection{Chemical Module}

\subsubsection{Gas Phase Chemistry Module}

[13] The chemical gas phase system LCC [Lurmann et al., 1987] (extended by Harley et al. [1993]) includes 44 gas phase species (of which 35 are transported and 9 are considered in steady state) coupled through 106 reactions. Originally, this system was developed to represent the photooxidation of nonmethane organic compounds (lumped into 12 precursors) and nitrogen oxides in urban-scale air quality simulation models. The numerical method used is the accurate and computationally efficient hybrid scheme of Young and Boris [1977]. Photolysis rate constants needed for photochemical reactions are prepared by means of the System for Transfer of Atmospheric Radiation (STAR) submodule [Ruggaber, 1994].

[14] Reactions of peroxiradicals and $\mathrm{HO}_{2}$ are terminal reactions for radicals. The mechanism includes the reactions of $\mathrm{RO}_{2}$ radicals with $\mathrm{HO}_{2}$ producing organic peroxides, but the organic peroxides themselves other than $\mathrm{H}_{2} \mathrm{O}_{2}$ are not traced further.

\subsubsection{Aerosol Module}

[15] Heterogeneous reactions are considered with the aerosol module SEQUILIB developed by Pilinis and Seinfeld [1987]. The SEQUILIB mechanism predicts the total quantity of ammonium, chloride, nitrate, and water contained in atmospheric aerosol, their physical state, and their distribution among aerosol particles of different sizes. The model is based on thermodynamic equilibrium calculation of the ammonium-chloride-nitrate-sodium-sulfate-water system. Especially designed for incorporation into a larger air quality model, it considers 22 different components: gas phase components $\left(\mathrm{NH}_{3}, \mathrm{HCl}, \mathrm{HNO}_{3}, \mathrm{SO}_{3}\right.$, and $\left.\mathrm{H}_{2} \mathrm{O}\right)$, liquid phase components $\left(\mathrm{H}_{2} \mathrm{O}, \mathrm{NH}_{4}, \mathrm{SO}_{4}, \mathrm{NO}_{3}, \mathrm{H}, \mathrm{Na}\right.$, $\mathrm{Cl}, \mathrm{HSO}_{4}$, and $\mathrm{H}_{2} \mathrm{SO}_{4}$ ), and solid phase components $\left(\mathrm{Na}_{2} \mathrm{SO}_{4}, \mathrm{NaHSO}_{4}, \mathrm{NaCl}, \mathrm{NaNO}_{3}, \mathrm{NH}_{4} \mathrm{NO}_{3}, \mathrm{NH}_{4} \mathrm{Cl}\right.$, $\left(\mathrm{NH}_{4}\right)_{2} \mathrm{SO}_{4}, \mathrm{NH}_{4} \mathrm{HSO}_{4}$, and $\left.\left(\mathrm{NH}_{4}\right)_{3} \mathrm{H}\left(\mathrm{SO}_{4}\right)_{2}\right)$.

[16] The gas-aerosol equilibrium is estimated taking into account, among others, four parameters: equilibrium constants, solute activity coefficient, water activity, and relative humidity of deliquescence. The first three properties determine the component concentrations, and the last one governs the maximum possible relative humidity at which a solid species can exist.

[17] The concentrations of $\mathrm{HCl}, \mathrm{NaCl}, \mathrm{NH}_{3}, \mathrm{HNO}_{3}$, and $\mathrm{H}_{2} \mathrm{SO}_{4}$ (which derive from the reaction simulated inside the aerosol module between $\mathrm{SO}_{3}$ and $\mathrm{H}_{2} \mathrm{O}$ ) as well as the relative humidity are given. The equilibrium concentrations of the possible compounds are identified using six regimes depending on the relative humidity. Then a system of thermodynamic and stochiometric equations is solved, together with the mass conservation and electroneutrality constraints to determine the equilibrium physical state and composition of the mixture.

[18] This aerosol module can only be regarded as a first step. It does not take into account chemical reactions in the liquid phase, or any reaction of odd $\mathrm{H}$ radicals $\left(\mathrm{OH}, \mathrm{HO}_{2}\right.$, and $\mathrm{RO}_{2}$ ) on aerosol surfaces. The only direct coupling between aerosol chemistry and photochemistry is the influence of the aerosol formation on the $\mathrm{HNO}_{3}$ levels that, in turn, influence the odd $\mathrm{H}$ levels over the reaction of $\mathrm{HNO}_{3}$ and $\mathrm{OH}$.

\subsubsection{Dry Deposition Module}

[19] The dry deposition flux in the lowest layer cells to the ground is represented by $\mathrm{F}_{\text {dep }}=\mathrm{v}_{\text {dep }} \mathrm{C}_{\text {(surface). The }}$ deposition is calculated with the resistance analogy and is the inverse value of the three resistances in series, the aerodynamic resistance $\left(R_{a}\right)$, the boundary layer resistance $\left(R_{b}\right)$, and the surface resistance $\left(R_{c}\right) . R_{a}$ and $R_{b}$ depend only on meteorological parameters, while $R_{c}$ is surface and species specific. $R_{a}$ and $R_{b}$ are expressed as a function of wind velocity, friction velocity, and the heat flux according to Businger et al. [1971] and Wesely and Hicks [1977].

\subsection{Model Setup}

\subsubsection{Domain}

[20] In the horizontal the simulated domain consists of 47 points in the east-west direction by 50 grid points in the north-south direction with a resolution of $3 \times 3 \mathrm{~km}$, covering the Lombardy region and the southern part of the Canton Ticino (Switzerland) (Figure 1). At the lateral boundaries, four additional grid cells (with a resolution of 3 , 6,12 , and $24 \mathrm{~km}$ ) are added in order to reduce the impact of the uncertainties in the boundary conditions on the domain 
of interest. In the vertical a terrain-following coordinate system with 24 levels is used with grid spacing increasing from $25 \mathrm{~m}$ at the surface to $1000 \mathrm{~m}$ near the model top (located at $8550 \mathrm{~m}$ ). This vertical grid stretching (ratio 1.2) is similar to that used in other studies [e.g., Clappier et al., 2000; Bornstein et al., 1996].

[21] TVM-LCC is able to calculate meteorological processes and transport/chemical processes on different grids. In this work, the chemical grid has the same horizontal resolution as the meteorological one but without the four boundary cells and has 15 vertical levels up to $4100 \mathrm{~m}$ above ground level.

\subsubsection{Emissions}

[22] In order to get a high spatial and temporal resolution (respectively $3 \times 3 \mathrm{~km}^{2}$ and 1 hour), a bottom-up approach has been chosen. Nonmethane volatile organic compounds (NMVOC) are speciated in storage and retrieval of aerometric data (SAROAD) classes on the basis of 11 different profiles (three biogenic and eight anthropogenic considering traffic, industrial, agricultural, and domestic activities) [Carter, 1995; Derwent et al., 1996]. The meteorological parameters used, when necessary, in emission estimate algorithms are relative to the specific day and hour of the simulation considered and to the specific municipality where the emission itself is calculated. The algorithms of Simpson et al. [1995] were used for seasonal and daily modulation of the biogenic emissions, tied to the changing of temperature, radiation, and humidity in the specific grid cell. The emission inventory was compiled by Maffeis et al. [1999].

[23] The VOC emissions are lumped to the 12 VOC classes of the LCC mechanism. Table 1 shows the average emissions per day.

[24] The highest emission densities are allocated to the metropolitan area of Milan and along the major highways that depart in a star-shaped formation from Milan. Averaging the whole model area, more than $90 \%$ of the CO emissions, about $50 \%$ of the $\mathrm{NO}_{x}$ emissions, and less than $30 \%$ of the VOC emissions result from traffic. Owing to the traffic, $\mathrm{CO}$ and $\mathrm{NO}_{x}$ emissions peak at 0900 and 1800 whereas VOC emissions are highest between 1000 and 1800 LT.

[25] Formation of secondary aerosol in the model is essentially driven by the $\mathrm{NH}_{3}$ emission that is not included in the available emission inventory prepared for the PIPAPO community. To simulate a reasonable spatial distribution of the $\mathrm{NH}_{3}$ emission, we used the $\mathrm{NH}_{3}$ emissions specified in the European Monitoring and Evaluation Programme (EMEP) inventory and distributed these emissions in the grid cells with land use categories appointed to agricultural activity.

\subsubsection{Initial and Boundary Conditions}

\subsubsection{Dynamical Calculation}

[26] The meteorological simulation starts at 2000 LT with horizontally homogeneous initial conditions based on the vertical sounding of the Linate Airport and last for 28 hours. These soundings show a free tropospheric wind from the southwest with variable speed from $2 \mathrm{~m} \mathrm{~s}^{-1}$ to $2.5 \mathrm{~m} \mathrm{~s}^{-1}$. The geostrophic wind and the wind velocity at the border are not changed during the simulation period. The hourly evolution of the temperature profiles at the borders is computed with a 1-D column model run initialized by the vertical sounding of Linate Airport. The first 4 hours of the simulation are considered as an initialization period, and the results are analyzed starting from 0000 LT.
Table 1. Time- and Space-Averaged Emissions Over the Domain for Different Species ${ }^{\mathrm{a}}$

\begin{tabular}{lc}
\hline \multicolumn{1}{c}{ Emitted Species } & Molecules cm ${ }^{-2} \mathrm{~s}^{-1}$ \\
\hline $\mathrm{NO}_{2}$ & $1.476 \mathrm{E}+10^{\mathrm{b}}$ \\
$\mathrm{NO}$ & $4.213 \mathrm{E}+11$ \\
$\mathrm{~N}_{2} \mathrm{O}_{5}$ & $1.307 \mathrm{E}+09$ \\
$\mathrm{SO}_{2}$ & $1.918 \mathrm{E}+11$ \\
$\mathrm{CO}$ & $1.093 \mathrm{E}+12$ \\
Methane & $1.043 \mathrm{E}+09$ \\
Higher alkanes & $2.651 \mathrm{E}+11$ \\
Ethene & $8.380 \mathrm{E}+10$ \\
Higher alkenes & $9.893 \mathrm{E}+10$ \\
Isoprene & $7.904 \mathrm{E}+10$ \\
Toluene and low reactive aromatics & $6.958 \mathrm{E}+10$ \\
Xylene and high reactive aromatics & $7.089 \mathrm{E}+10$ \\
Methanol & $1.410 \mathrm{E}+08$ \\
Higher alcohols & $8.836 \mathrm{E}+10$ \\
Formaldehyde & $1.809 \mathrm{E}+10$ \\
Higher aldehydes & $3.197 \mathrm{E}+10$ \\
Ketones & $2.302 \mathrm{E}+10$ \\
$\alpha-$ Pinene and other terpenes & $7.904 \mathrm{E}+10$ \\
$\mathrm{NH}_{3}$ & $3.226 \mathrm{E}+11$ \\
Elemental carbon, diameter $0.04-0.15 \mu \mathrm{m}$ & $2.715 \mathrm{E}+12$ \\
Elemental carbon, diameter $0.15-0.62 \mu \mathrm{m}$ & $1.659 \mathrm{E}+12$ \\
Elemental carbon, diameter $0.62-2.50 \mu \mathrm{m}$ & $1.377 \mathrm{E}+12$ \\
Elemental carbon, diameter $2.50-10.0 \mu \mathrm{m}$ & $8.066 \mathrm{E}+11$ \\
Organic aerosols, diameter $0.04-0.15 \mu \mathrm{m}$ & $6.495 \mathrm{E}+12$ \\
Organic aerosols, diameter $0.15-0.62 \mu \mathrm{m}$ & $3.969 \mathrm{E}+12$ \\
Organic aerosols, diameter $0.62-2.50 \mu \mathrm{m}$ & $3.294 \mathrm{E}+12$ \\
Organic aerosols, diameter $2.50-10.0 \mu \mathrm{m}$ & $1.930 \mathrm{E}+12$ \\
Crustal aerosols, diameter $0.04-0.15 \mu \mathrm{m}$ & $3.034 \mathrm{E}+12$ \\
Crustal aerosols, diameter $0.15-0.62 \mu \mathrm{m}$ & $1.854 \mathrm{E}+12$ \\
Crustal aerosols, diameter $0.62-2.50 \mu \mathrm{m}$ & $1.539 \mathrm{E}+12$ \\
Crustal aerosols, diameter $2.50-10.0 \mu \mathrm{m}$ & $9.015 \mathrm{E}+11$ \\
\hline${ }^{a}$ Emission values are expressed in number of molecules per cm ${ }^{-2} \mathrm{~s}^{-1}$ \\
${ }^{b}$ Read $1.476 \mathrm{E}+10$ as $1.476 \times 10^{10}$. & \\
&
\end{tabular}

\subsubsection{Chemical Calculation}

[27] The model domain under investigation is rather small. Boundary conditions can therefore influence the calculated concentrations, especially for longer-lived species. For this reason it was essential for us to use boundary conditions showing the following characteristics: (1) The $\mathrm{O}_{3}$ and $\mathrm{NO}_{x}$ concentrations used at the boundaries must be in agreement with the background measured during the night in the rural areas (station category 3 described in section 4.1); and (2) a complete and chemically consistent set of species must be specified at the boundaries.

[28] In order to produce this set of species, a multiday run of the model in a 1-D (along the vertical) mode with average emissions of the Po Valley south of Milan was used. After 8 days of simulations, $\mathrm{O}_{3}$ and $\mathrm{NO}_{x}$ concentrations did not change significantly from one day to the other and were very close to the measured background values (Figure 2). The results of this simulation were used as initial conditions and boundary conditions for the southern, western, and eastern borders. At the northern border, being on the Alps far from important pollutant sources, constant boundary conditions representing standard free tropospheric concentrations have been used $\left(\mathrm{O}_{3}=50 \mathrm{ppb}\right.$, $\mathrm{NO}=0.1 \mathrm{ppb}, \mathrm{NO}_{2}=0.1 \mathrm{ppb}$ ).

[29] A first simulation starts at 0000 LT and runs for 24 hours to generate the initial conditions of a second 24 hour run. Since the meteorological conditions were very similar on 12 and 13 May, the same wind, turbulence, and temperature fields are used for the two days (this methodology to set up the initial conditions for a photochemical simulation 

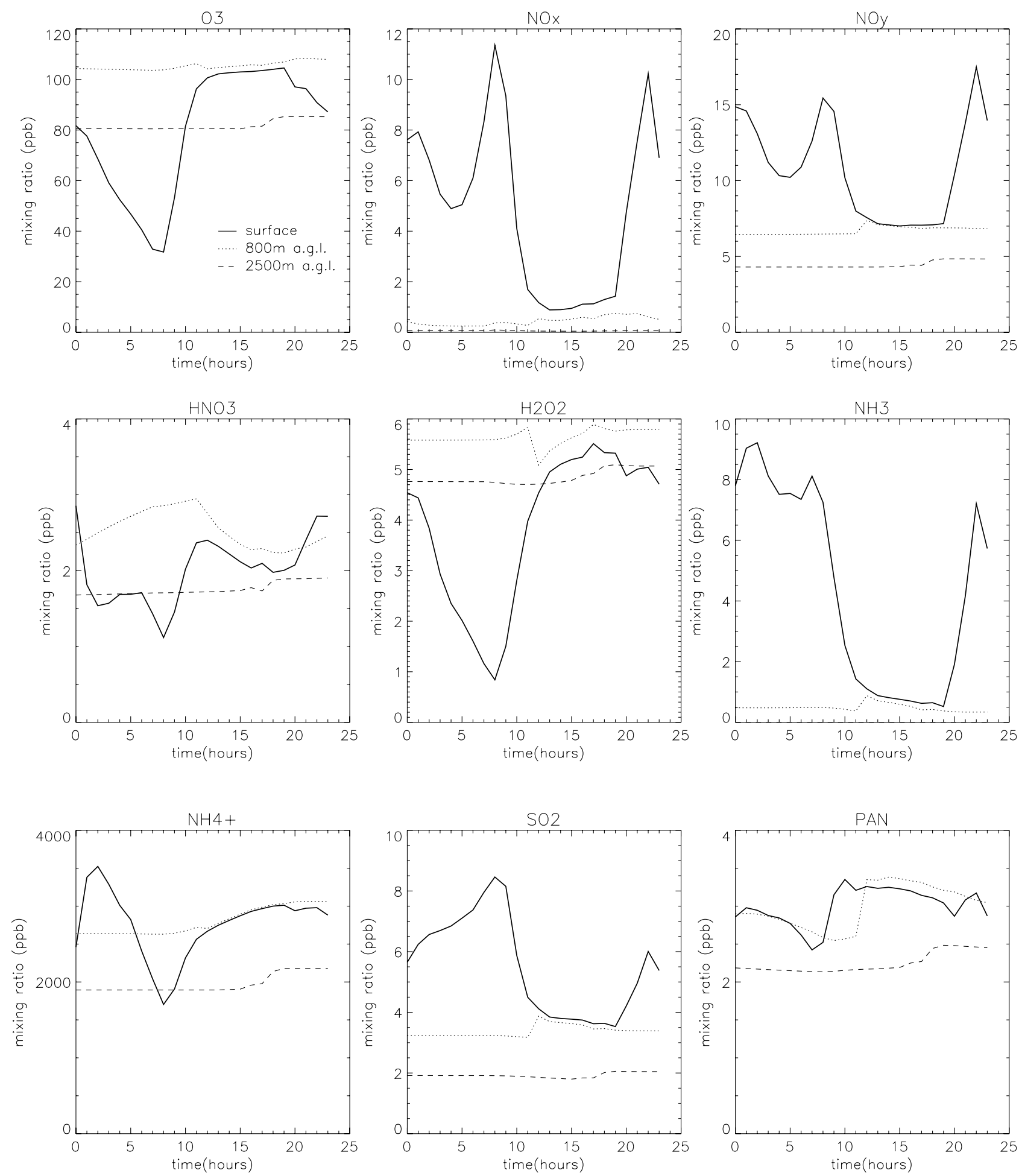

Figure 2. Diurnal $\mathrm{O}_{3}, \mathrm{NO}_{x}, \mathrm{NO}_{y}, \mathrm{HNO}_{3}, \mathrm{H}_{2} \mathrm{O}_{2}, \mathrm{NH}_{3}, \mathrm{NH}_{4}^{+}, \mathrm{SO}_{2}$, and peroxyacetyl nitrate (PAN) variation used for the western, southern, and eastern boundary conditions.

has already been used in the past [e.g., Giovannoni and Russell, 1995].

\section{Model Results Compared With Measurements}

[30] The model was set up to simulate the temporal and spatial evolution of photo-oxidants during the first IOP of
13 May. The focus was set on the region between the metropolitan area of Milan and the foothills of the Alps.

\subsection{Atmospheric Circulation}

[31] The first intensive measuring period of the PIPAPO campaign (12-13 May 1998) was characterized by the presence of a well-established anticyclone of the Azores, 

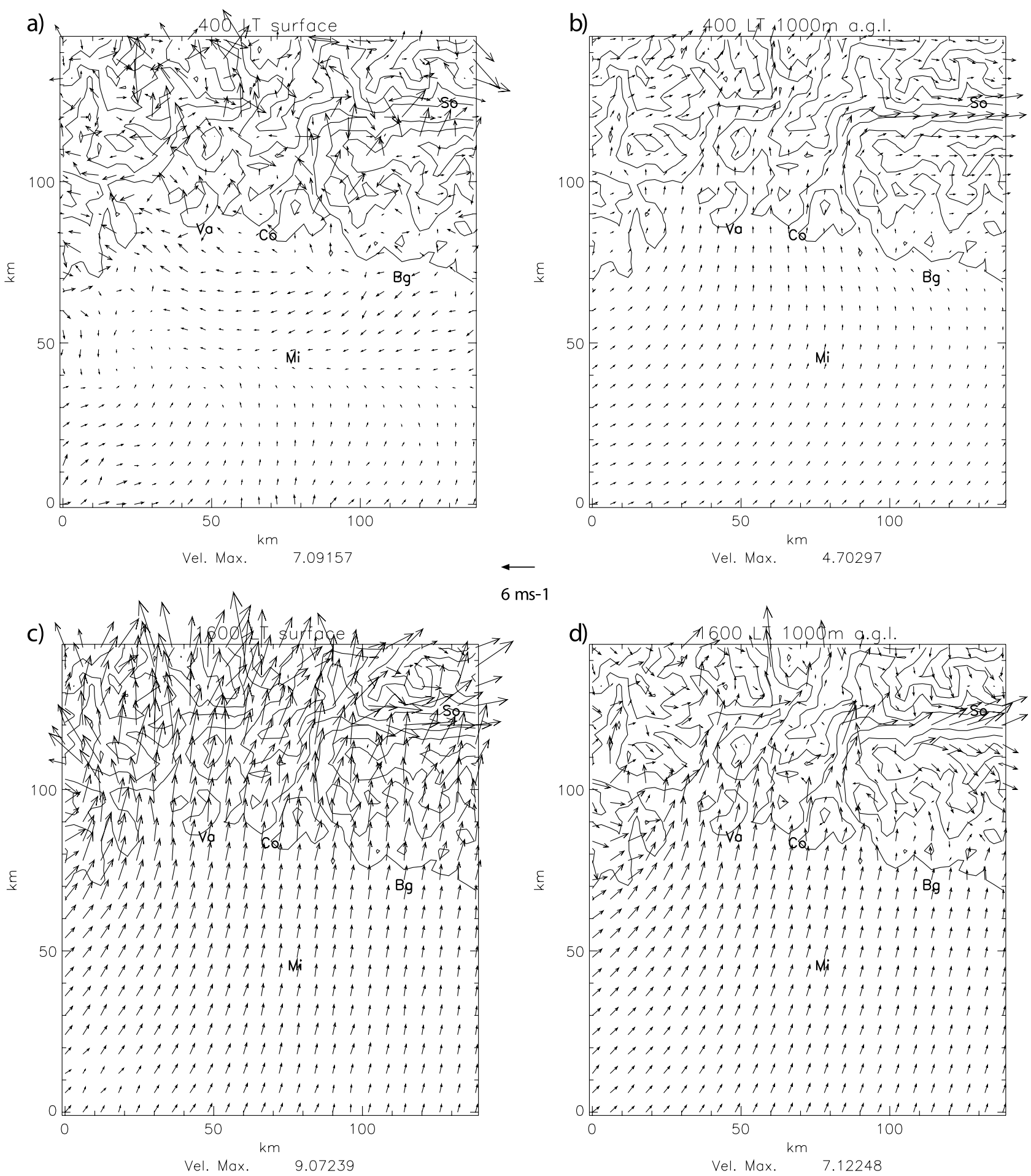

Figure 3. Wind fields at $0400 \mathrm{LT}$ (a) at the ground level, (b) at $1000 \mathrm{~m}$ above ground level (agl); and at $1600 \mathrm{LT}$, (c) at the ground level, and (d) at $1000 \mathrm{~m}$ agl.

extending its influence into the Mediterranean Sea and over the Alps. As a consequence, mesoscale and local effects mainly caused the circulation over the Po Valley region: in particular, anabatic-katabatic flows and mountain-valley winds induced by the presence of the Alps in the north of the domain. The horizontal wind fields at the first computational level $(25 \mathrm{~m}$ depth $)$ and at $1000 \mathrm{~m}$ above ground for the hours of 0400 and 1600 are shown in Figure 3.

[32] During the night, model results show downslope flows in the main alpine valleys. These flows also influence the circulation in the central part of the domain where weak northeasterly winds are simulated. In the Milan urban area and in the southern part of the domain, winds are very low 


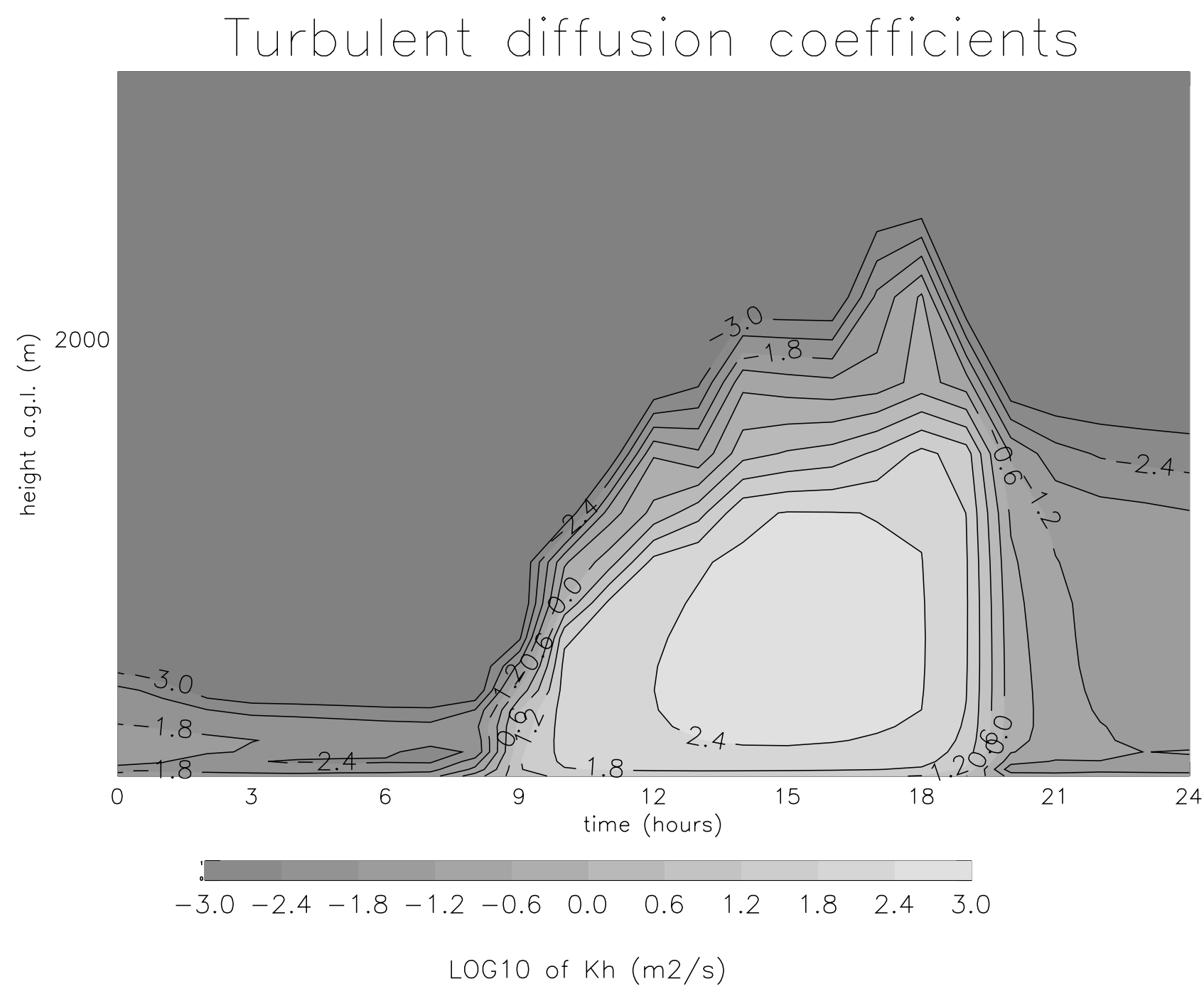

Figure 4. Two-dimensional contour plot of computed K-values (height versus time) of turbulent diffusion coefficients.

and mainly from the southwest (direction of the synoptic wind). In the daytime period the wind fields generated by the model (Figure 3) are characterized by a strong flow toward the north induced by the anabatic and the valley winds generated by the Alps. All these results are in agreement with the available measurements (not shown).

[33] The turbulent mixing in the boundary layer is the primary factor that influences the dilution of the emission and thus has a crucial influence on the chemical processes. The simulation of the vertical turbulent exchange determines how fast emissions are lifted upward and consequently has a large influence on the concentration of $\mathrm{O}_{3}$ precursors and therefore also on the chemistry of $\mathrm{O}_{3}$ formation. Figure 4 shows a contour plot of the diurnal variation of the exchange coefficients calculated by the model.

[34] During the first IOP of the PIPAPO campaign (13 May) several measurements of the mixing height were taken with different instrumentation: a wind profiler (in Seregno), balloon soundings (in Linate), a Lidar (in Seregno), and an airplane. The comparison between these measurements and the simulation raises two problems: The first problem is that the measured and the simulated mixing heights are based on the vertical gradient change of different atmospheric parameters: the wind profiler and the balloon measurements used the temperature profile, the Lidar, and the airplane used the aerosol and $\mathrm{O}_{3}$ profile, and the model used the turbulent kinetic energy (TKE). In Figure 5a a comparison of these measurements with an average mixing height in the Po Valley computed by the model is presented. Considering the variation in the experimental data the agreement is particularly good. The second problem is that the minimum level of these measurements (few hundred meters) is too high to estimate precisely the mixing height during nighttime and in the early morning. Nevertheless, complementary information about the rising of the mixing height can be deduced from the ${ }^{222} \mathrm{Rn}$ measurements. Assuming a constant ground emission rate of ${ }^{222} \mathrm{Rn}$, it has been shown that ${ }^{222} \mathrm{Rn}$ concentrations are strongly correlated with the mixing in the Po Valley [Allegrini et al., 1994; Sesana et al., 1998]. A simulation of ${ }^{222} \mathrm{Rn}$ concentration has been performed, and the results are compared with measurements at Landriano and Brera (Figure 5b). In the morning the decrease time of the ${ }^{222} \mathrm{Rn}$ concentration computed by the model is in good 
a)

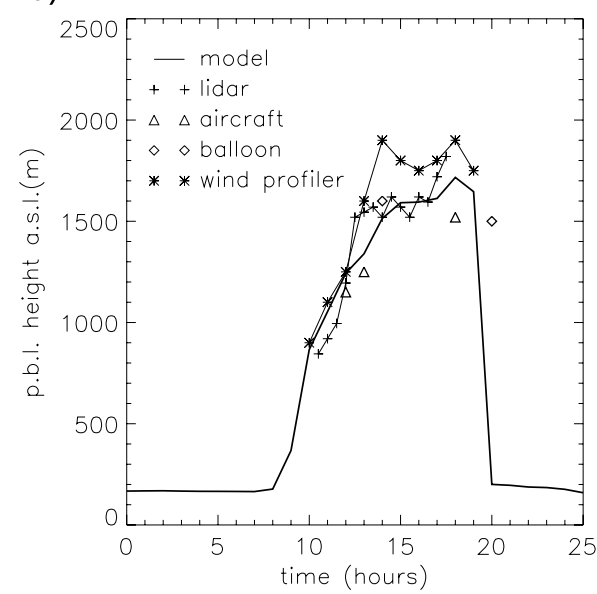

b)

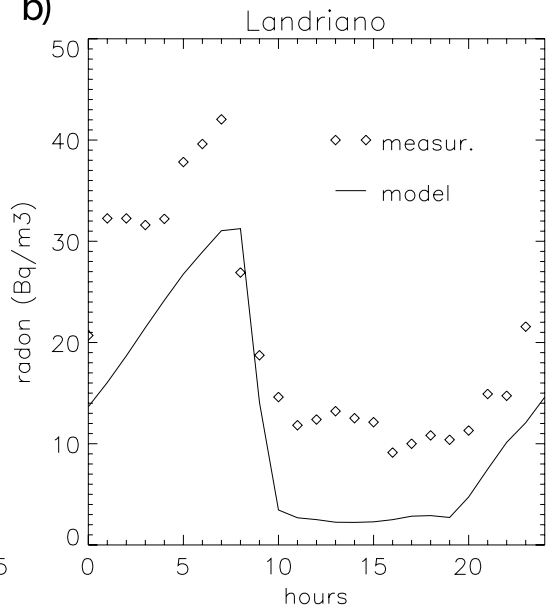

c)

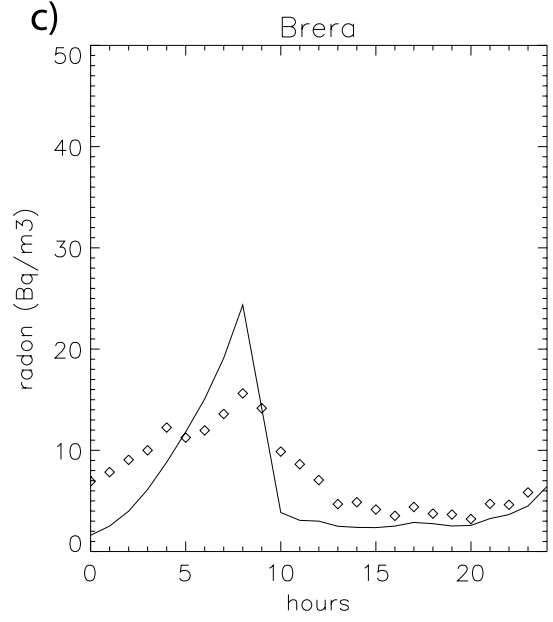

Figure 5. Comparison concerning the measured and simulated mixing height: (a) Estimation of the mixing height over the day using the simulated turbulent kinetic energy and different measured vertical profiles. Comparison between simulated and measured ${ }^{222} \mathrm{Rn}$ concentrations (b) at Landriano and (c) at Brera.

agreement with the measurements, meaning that the increase time of the mixing height is well captured.

\subsection{Chemistry}

\subsubsection{Horizontal Distribution of $\mathrm{O}_{3}$}

[35] The purpose of the model application is the investigation of the $\mathrm{O}_{3}$ production sensitivity in the Milan region during strong $\mathrm{O}_{3}$ episodes. Consequently, the comparison between the simulation and a large set of available measurements for $\mathrm{O}_{3}$ is a necessary step of the validation.

[36] In order to find a structure in the $\mathrm{O}_{3}$ spatial distribution, Figure 6 suggests a simple classification of the measurement stations in relation to the proximity to emission sources. Using the average $\mathrm{O}_{3}$ concentration measured during the night (between 0000 LT and 0700 LT) and the $\mathrm{O}_{3}$ maximum reached during the day, the ground stations can be classified in three different categories (Figure 1): Category 1 stations have very low nighttime concentrations $(0$ to $30 \mathrm{ppb}$ ) and low maxima (100 to $150 \mathrm{ppb}$ ): Milano, Magadino, Bresso, Brera, and Laveno. Category 2 stations have low nighttime concentrations (30 to $60 \mathrm{ppb}$ ) and low maxima (100 to $150 \mathrm{ppb}$ ): Nibionno, Cavenago, Varese, Colico, Como, Merate, Seregno, and Lugano. Category 3 stations have high nighttime concentrations (60 to $110 \mathrm{ppb}$ ) and high maxima (160 to $190 \mathrm{ppb}$ ): Verzago, Alpe del vicere, Erba, Torno, and Varenna.

[37] This classification can be used to locate the different stations in relation to the pollution sources. The low $\mathrm{O}_{3}$ levels during the night are mainly due to the destruction of $\mathrm{O}_{3}$ reacting with the $\mathrm{NO}_{x}$. One can conclude that the stations of category 1 are close to important sources of primary pollutants, while the stations of category 3 are far from these sources. During the day, with high levels of $\mathrm{NO}_{x}$ inhibiting $\mathrm{O}_{3}$ formation, the stations of category 1 show relatively low $\mathrm{O}_{3}$ maxima. On the other hand, the high $\mathrm{O}_{3}$ concentrations of category 3 indicate that these stations are located where the photochemical smog is detected. The $\mathrm{O}_{3}$ maxima between 160 to $190 \mathrm{ppb}$ appear around 1400 LT to 1500 LT in the region of Verzago, Erba, Alpe del vicere, and Torno and 1 hour later in Varenna (Figure 7). Category 2 is an intermediate step between categories 1 and 3. Figure 1 shows that some of the stations of category 2 are, effectively, located between the primary pollutant sources (category 1 ) and the $\mathrm{O}_{3}$ maxima (category 3 ).

[38] The structure of the $\mathrm{O}_{3}$ distribution in the area under consideration shows a good correspondence between the network data and the model results. Especially, the peak $\mathrm{O}_{3}$ concentration is well reproduced. The simulated photochemical smog appears around 1200 LT at the west of Milan (Figure 8) before being transported in the north direction by the up-slope winds. The model simulates an $\mathrm{O}_{3}$ maximum of $188 \mathrm{ppb}$ at 1600 LT a few kilometers east

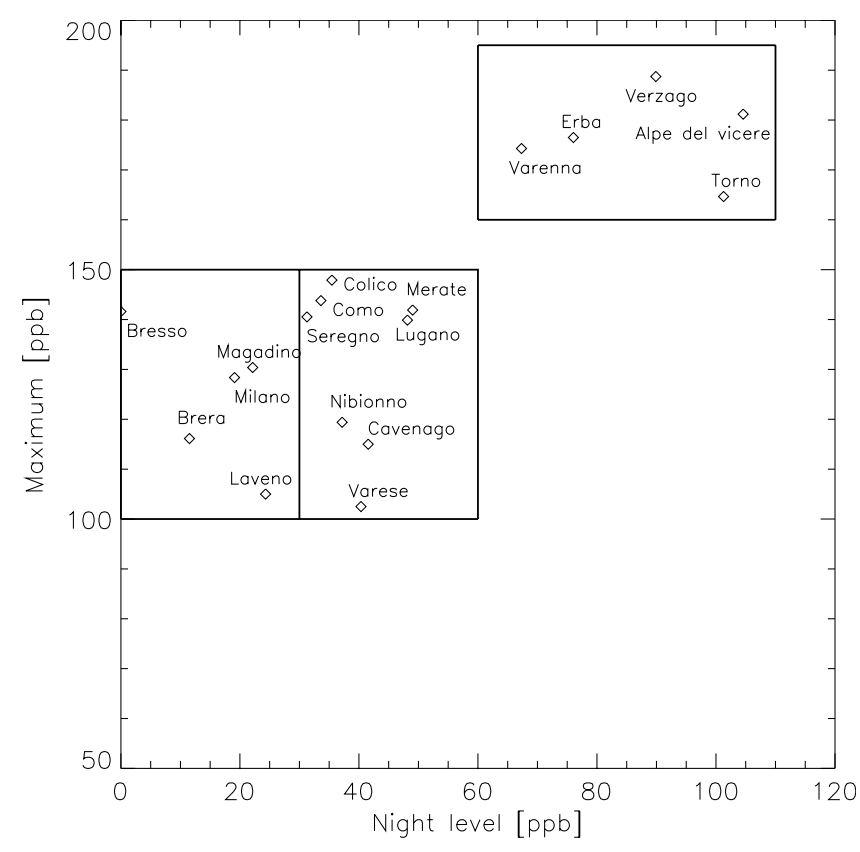

Figure 6. Ground station classification using the average nighttime $\mathrm{O}_{3}$ concentrations and the daily maximum $\mathrm{O}_{3}$ concentration. 
a)
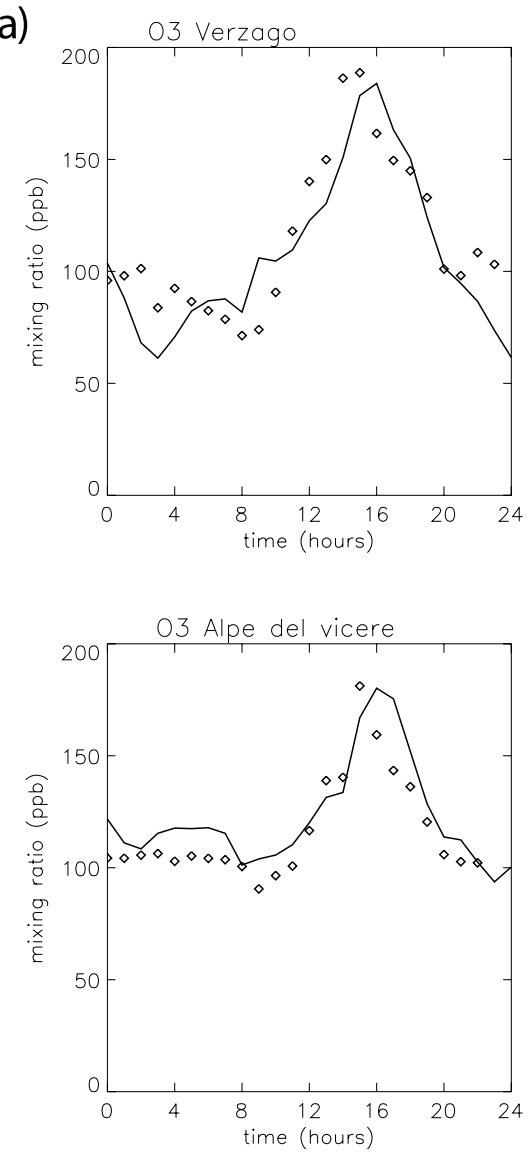
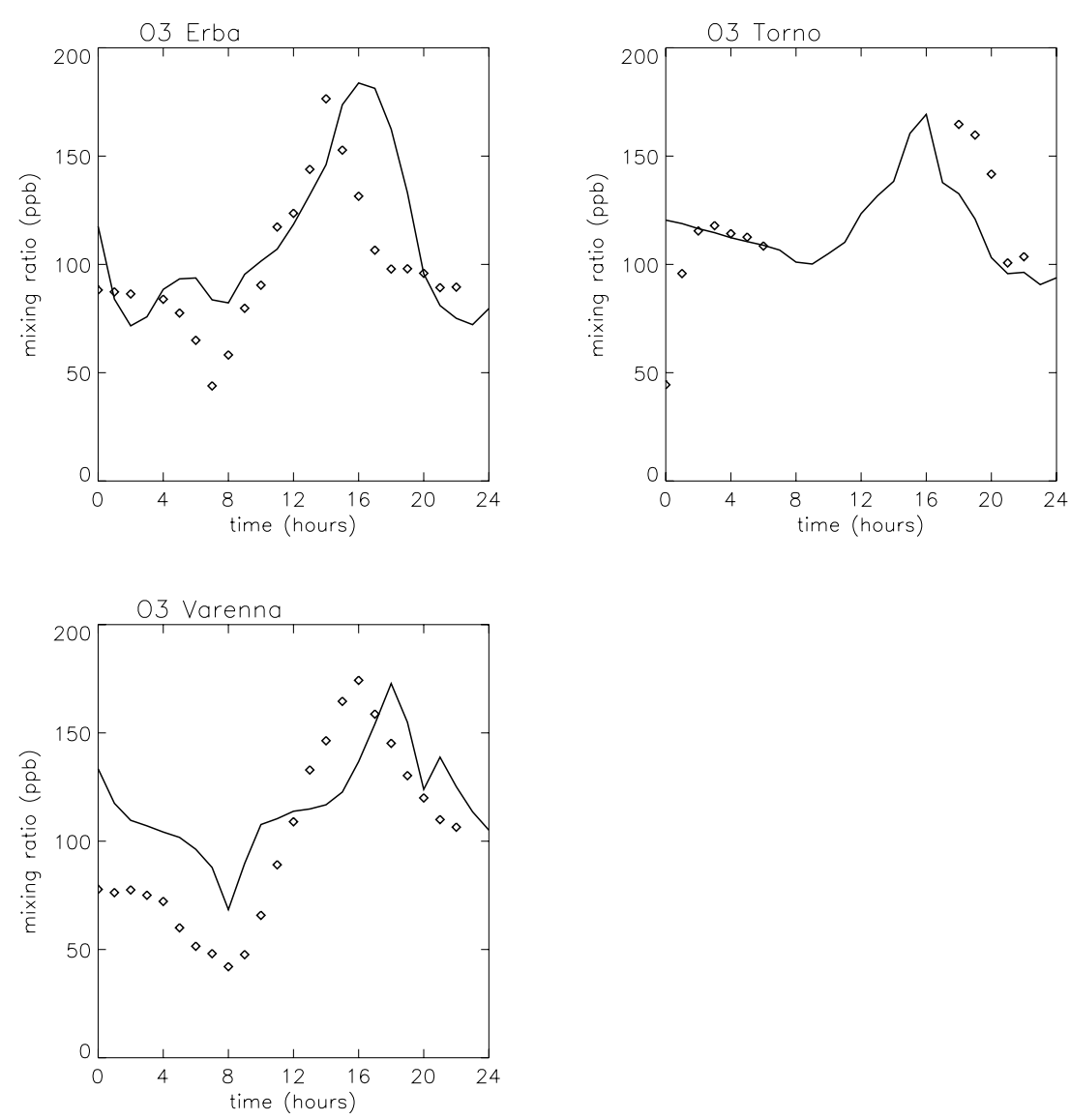

Figure 7. Comparison between simulated (solid line) and measured (diamonds) $\mathrm{O}_{3}$ at different ground stations (a) of category 1 , (b) of category 2, and (c) of category 3.

of Verzago. It corresponds to the range found at the stations of category 3 (between 160 to $190 \mathrm{ppb}$ ) and to the measured maximum in Verzago (190 ppb). In the measurements the $\mathrm{O}_{3}$ maximum appears around $1400 \mathrm{LT}$ in Verzago, while the simulated smog reaches this region with 2 hours delay at 1600 LT (Figure 7).

[39] Concerning the $\mathrm{O}_{3}$ concentrations during nighttime, the agreement between the simulation and the measurement is reasonably good. The model simulates correctly the high nighttime concentrations of category 3 (Figure 7). The low $\mathrm{O}_{3}$ concentrations resulting from the reactions with the $\mathrm{NO}_{x}$ is well reproduced over the Po Valley (Milano, Bresso, Brera, Nibionno, Cavenago, Como, and Merate). Major deviations, owing to an underestimation of the simulated $\mathrm{O}_{3}$, can be seen during the night for stations located in the alpine valley (Magadino, Colico, and Lugano).

\subsubsection{Distribution of Different Pollutants Along the Plume Trajectory}

[40] During the PIPAPO field experiment two "supersites" have been in operation situated along the plume trajectory: Bresso and Verzago. The large number of measurements done on these sites allows the comparison between the measurements and the simulation for many species related to the $\mathrm{O}_{3}$ and aerosol formation. These comparisons, shown in Figure 9, suggest the three following remarks:

1. Systematically, higher nighttime values are simulated in the model for most of the emitted pollutants. Several weaknesses in the model formulation can explain the systematic emitted pollutant overestimation during the night:

The turbulent fluxes in the surface layer are estimated using the Monin Obukhov similarity theory in the formulation of Businger et al. [1971]. This formulation is not adapted to simulate accurately the turbulence vertical structure in urban areas. Moreover, the computation of the ground surface temperature does not take into account the shadowing and radiative trapping effects induced by the presence of buildings. Consequently, the simulated nocturnal mixing height is underestimated over the urban areas. On the other hand, the largest part of primary pollutants is emitted in urban areas. The combination of these two factors leads to the trapping of the emitted species in the first layer cells (close to the ground) during nighttime.

Since the formulation of the deposition velocity in the model is coupled to the parameterization of the vertical mixing, a weak mixing also means a low deposition velocity. Moreover, in the deposition module used in the TVM-LCC model the parameterization assumed that the surface resistance $\left(R_{c}\right)$ is the same for all the species and that there is no minimum for the deposition velocity. For very stable conditions that are typically present for nighttime in the simulation, the deposition velocity is unrealistically small. The underestimation of the deposition velocity can contribute to the overestimation of the species.

2 . The simulation catches the plume arrival in Verzago. In the measurements the pollution plume reaches Verzago 
b)
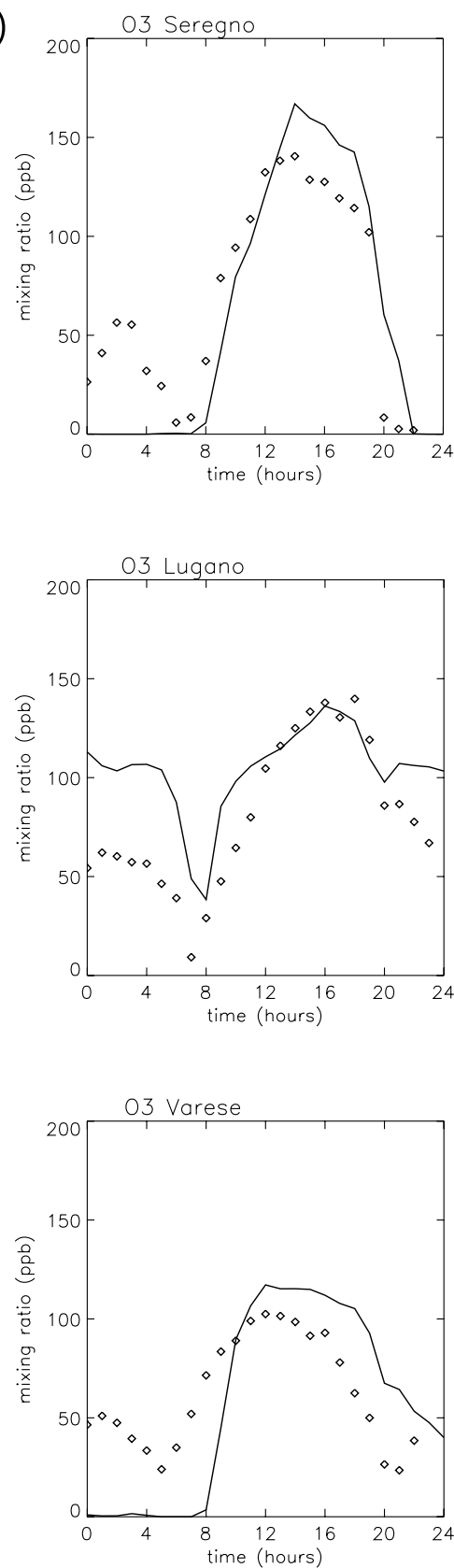
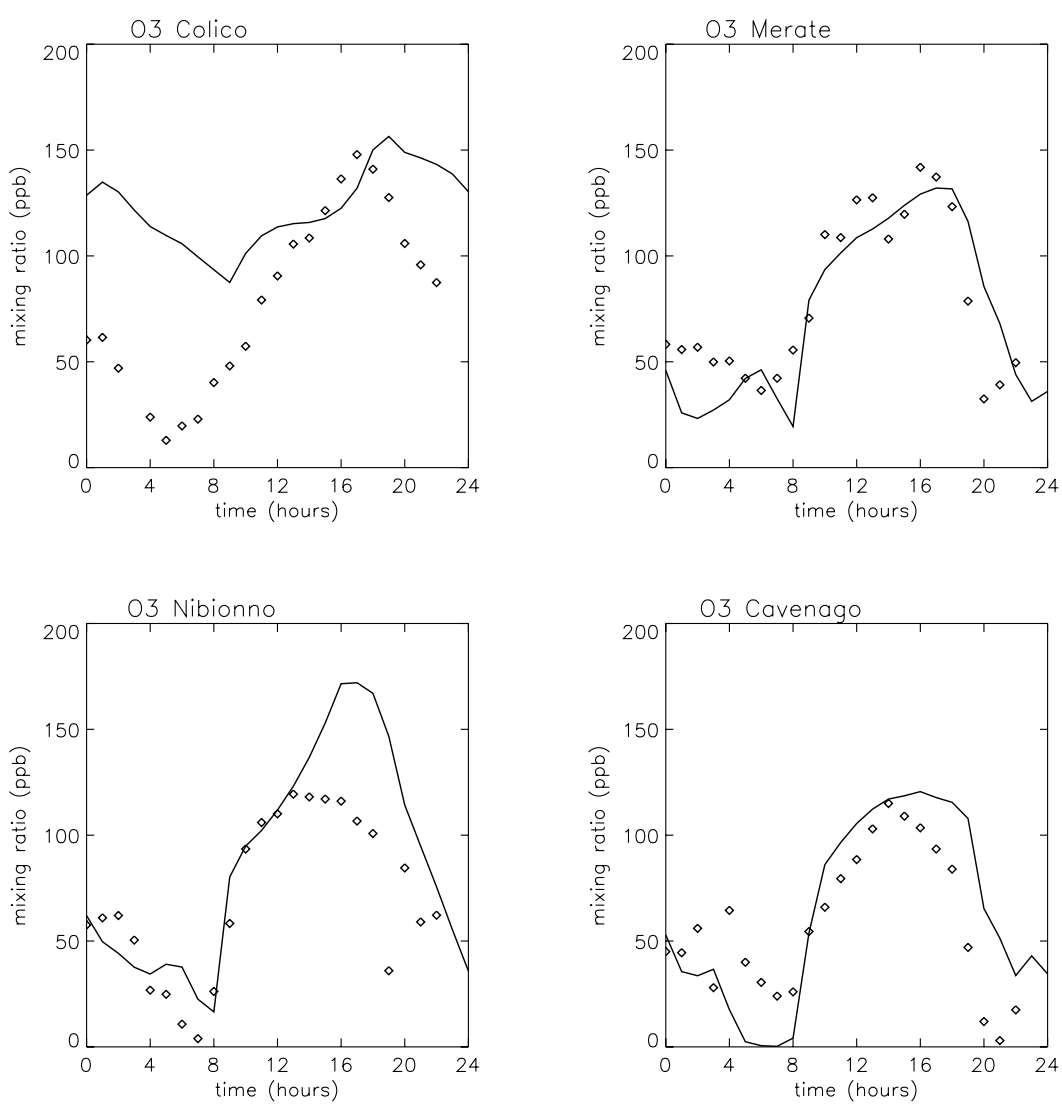

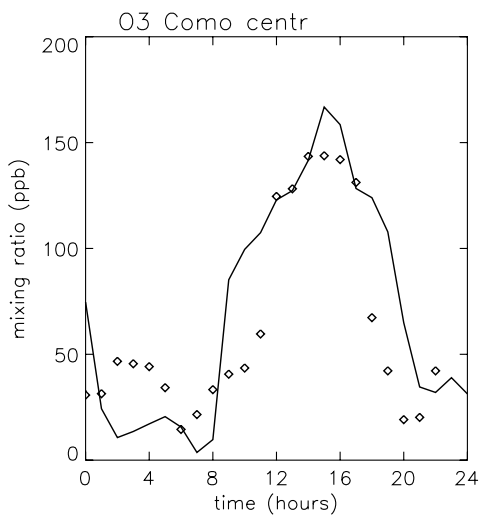

Figure 7. (continued) around $1400 \mathrm{LT}$ and is accompanied by an enhancement of different chemical species: $\mathrm{O}_{3}, \mathrm{NO}_{y}, \mathrm{NO}_{2}, \mathrm{NO}, \mathrm{HNO}_{3}$, peroxyacetyl nitrate (PAN), VOCs, $\mathrm{HCHO}, \mathrm{NO}_{3}^{-} \ldots$ On the contrary, the $\mathrm{H}_{2} \mathrm{O}_{2}$ concentrations are slightly lower in the plume. In the simulation the plume is delayed by 1 or 2 hours; it reaches Verzago between 1500 and 1600 LT. As a consequence, compared to the measurements, the simulated plume chemistry is further aged. Table 2 gives an overview of the different pollutant concentrations in the simulated and the measured plume. It shows that the model is in relatively good agreement with the measurements for $\mathrm{O}_{3}, \mathrm{NO}_{y}$, VOCs (propene-equivalent carbon PRPQ), and $\mathrm{NO}_{3}^{-}$. On the other hand, the model did not simulate the $\mathrm{NO}$ and $\mathrm{NO}_{2}$ enhancement and overestimates the PAN and $\mathrm{HNO}_{3}$ concentrations. There are several possible reasons for such a discrepancy:

This $\mathrm{HNO}_{3}$ overprediction has been seen before in model calculations [Sillman et al., 1998]. Hall and Claiborn [1997] reported dry deposition velocities for $\mathrm{H}_{2} \mathrm{O}_{2}$ (and presumably for $\mathrm{HNO}_{3}$ ) as high as $5 \mathrm{~cm} \mathrm{~s}^{-1}$, more than twice as high as the values commonly used in chemical transport models.

Recently, new measurements resulted in a $20-30 \%$ lower rate constant for the formation reaction $\mathrm{NO}_{2}+\mathrm{OH}$ than currently introduced in mechanisms [Brown et al., 1999], suggesting an overestimation of the produced $\mathrm{HNO}_{3}$ 
c)
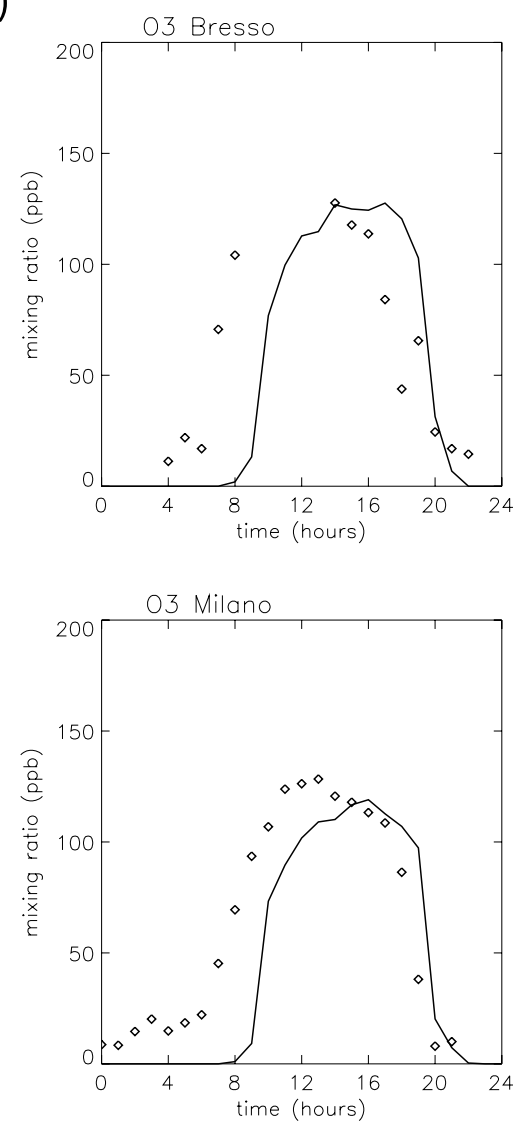
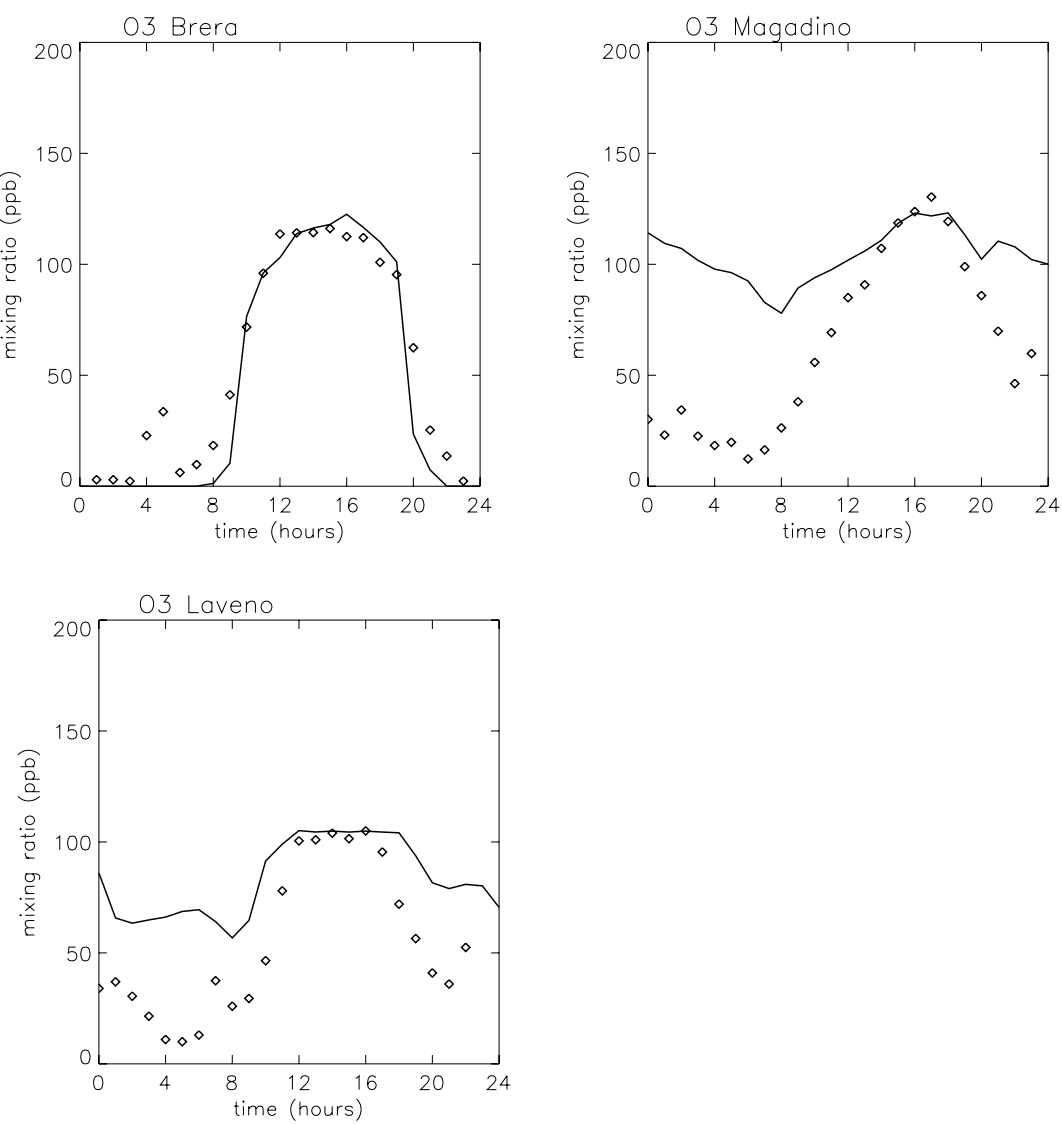

Figure 7. (continued) in the model. On the other hand, there might also be an underestimation in the measured $\mathrm{HNO}_{3}$ mixing ratios, because $\mathrm{HNO}_{3}$ measurements are easily biased by losses in inlet lines and near-surface gradients.

Measured PAN values are roughly half of the modeled concentrations. In the model, PAN is a lumped species that corresponds to the sum of all acyl peroxynitrates, whereas the measured PAN is restricted to acetyl peroxynitrate. By the way, the measured $\mathrm{NO}_{y}$ is $33 \%$ higher then the sum of measured reactive nitrogen components $\left(\mathrm{NO}, \mathrm{NO}_{2}, \mathrm{HONO}\right.$, $\mathrm{PAN}$, and $\mathrm{HNO}_{3}$ ). A portion of this unidentified $\mathrm{NO}_{y}$ may be other peroxynitrates. In American field campaigns it was found that the concentrations of propionyl peroxynitrate (PPN), n-butyryl peroxynitrate (PnBN) and methacryloyl peroxynitrate (MPAN) can reach concentrations of $10-30 \%$, $8 \%$, and $10-30 \%$, respectively, of the PAN concentrations [Grosjean et al., 1993a, 1993b; Davidson, 1993; Williams and Grosjean, 1991; Williams et al., 1993]. Comparisons between the RADM2 and the RACM mechanism show that the implemented $\mathrm{RO}_{2}$ chemistry, using the older kinetic data of the RADM2 mechanism [Stockwell et al., 1997], which are similar to the LCC mechanism data, can considerably overestimate the results for PAN.

The comparison of the aerosol species with the measurements relies on only a few measurements in Verzago and Bresso and can therefore only be indicative as to whether this first approach to include the aerosols yields the right order of magnitude. A major uncertainty is the crude parameterization of the $\mathrm{NH}_{3}$ emissions owing to the absence of a detailed emission inventory. Emissions are concentrated in the southeast corner of the domain, where no measurements are available. Modeled and measured concentrations in Verzago of $\mathrm{NH}_{3}, \mathrm{NH}_{4}^{+}$, and $\mathrm{NO}_{3}^{-}$ correspond well for well-mixed conditions in the afternoon, while measured $\mathrm{SO}_{2}$ and $\mathrm{SO}^{4-}$ concentrations are much lower than the modeled ones. Calculated $\mathrm{NH}_{3}$ concentrations are highest in the southeast corner of the model domain, but can not be validated. The good correspondence of the $\mathrm{NO}^{3-}$ and $\mathrm{NO}_{y}$ levels both in Bresso and Verzago gives us confidence that the effect of the secondary aerosol formation on the indicator ratios $\mathrm{H}_{2} \mathrm{O}_{2} / \mathrm{HNO}_{3}$ and $\mathrm{O}_{3} / \mathrm{NO}_{z}$ is correctly described.

3. The levels for $\mathrm{SO}_{2}$ and $\mathrm{SO}_{4}^{2-}$ are systematically higher in the model than in the measurements, and the opposite is true for $\mathrm{CO}$. Because only very small parts of the amounts of the $\mathrm{CO}, \mathrm{NO}_{y}$, and $\mathrm{SO}_{x}\left(=\mathrm{SO}_{2}+\mathrm{SO}_{4}^{2-}\right)$ are removed by loss reactions (chemical reactions or dry deposition), these species can approximately be regarded as conservative tracers for the simulation period. During the day the simulated results compared with the measurements for these three species show systematically higher levels for $\mathrm{SO}_{2}$ and $\mathrm{SO}_{4}^{2-}$ in the model, the opposite for $\mathrm{CO}$, and a relatively good agreement for $\mathrm{NO}_{y}$. Consequently, the most reasonable explanation of the systematically too high levels of $\mathrm{SO}_{x}$ and too low levels of $\mathrm{CO}$ is an overestimation of the $\mathrm{SO}_{2}$ emissions and an underestimation of the $\mathrm{CO}$ emissions. An underestimation of the $\mathrm{CO}$ emissions biases the $\mathrm{O}_{3}$ chemistry toward VOC sensitivity. Because in the 
a)
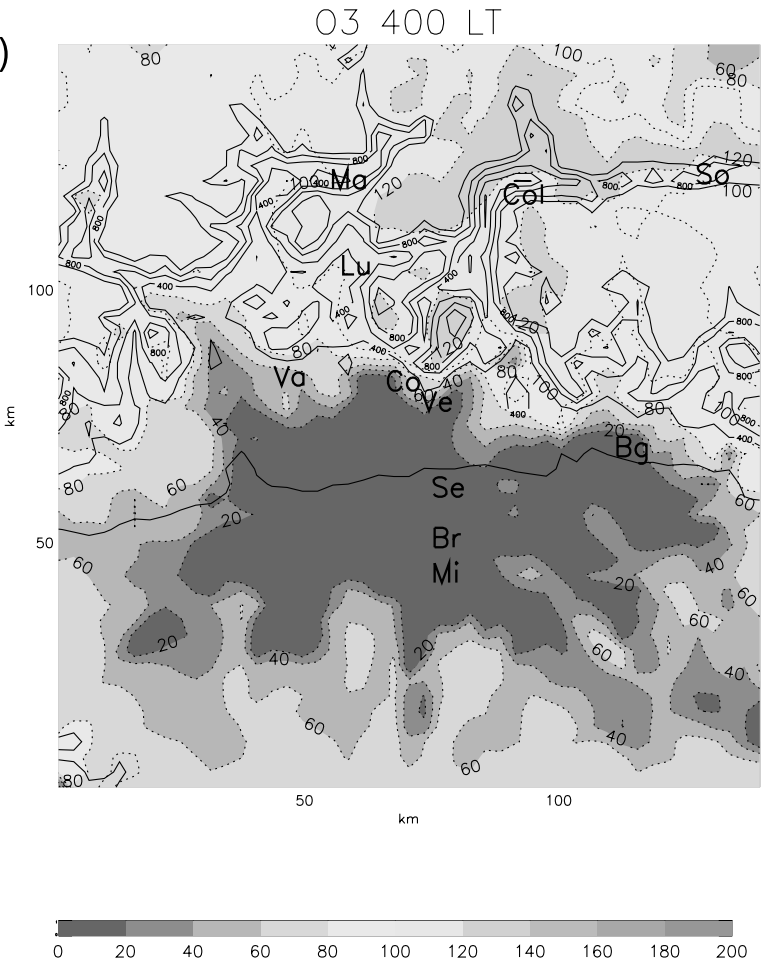

$\mathrm{ppb}$ b)
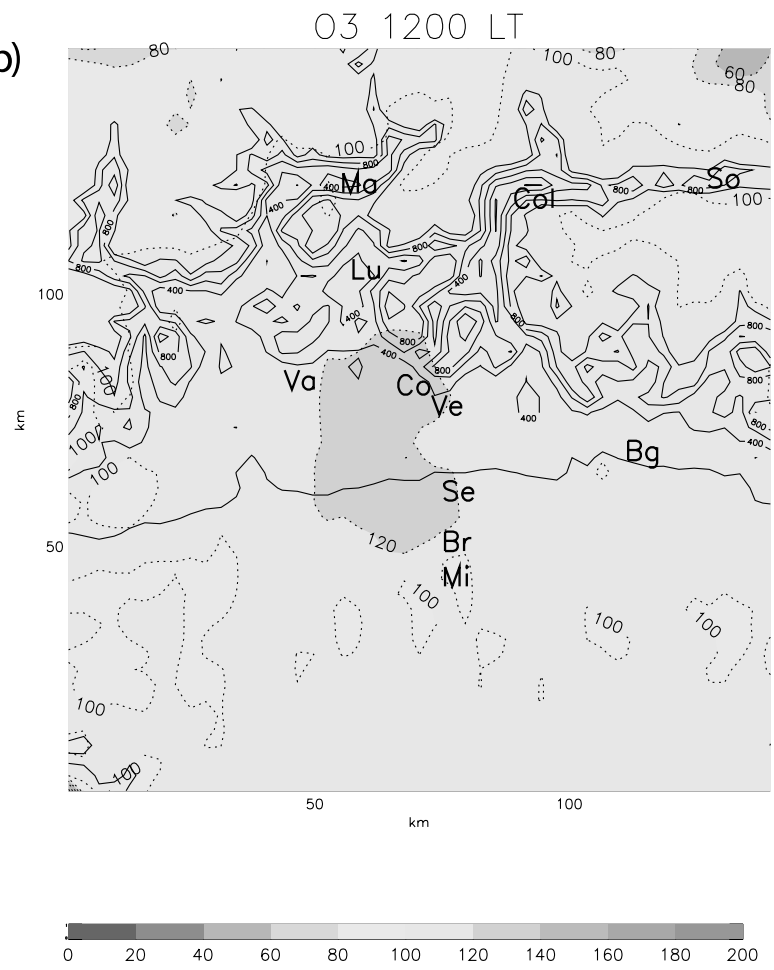

c)

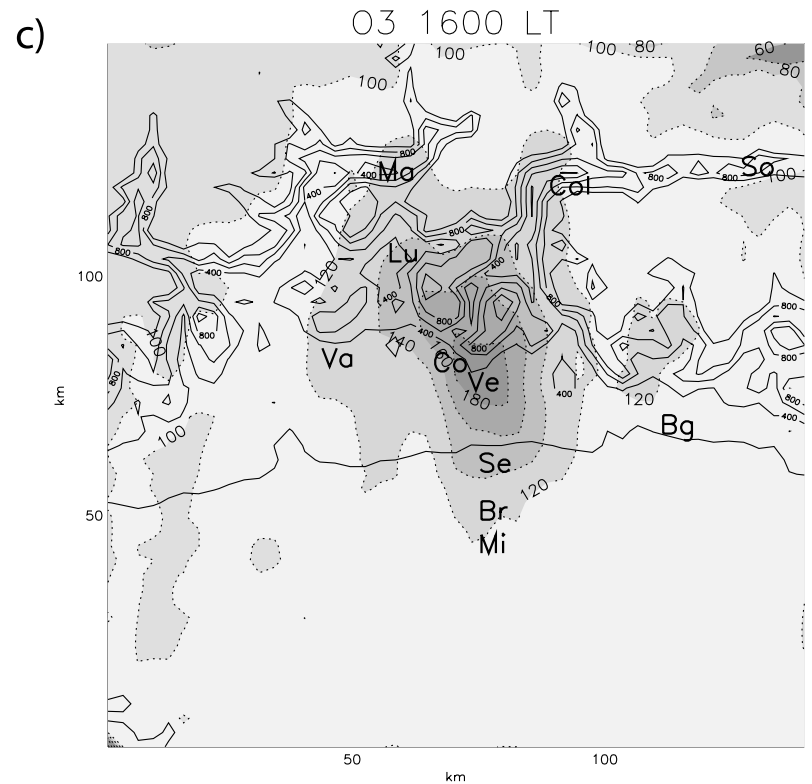

$\mathrm{ppb}$

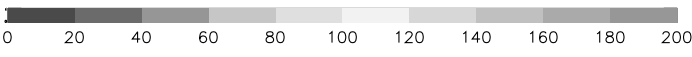

$\mathrm{ppb}$

Figure 8. Simulated $\mathrm{O}_{3}$ values within the first vertical layer (30 m) at (a) $0400 \mathrm{LT}$, (b) $1200 \mathrm{LT}$, and (c) 1600 LT. See color version of this figure at back of this issue. 
a)
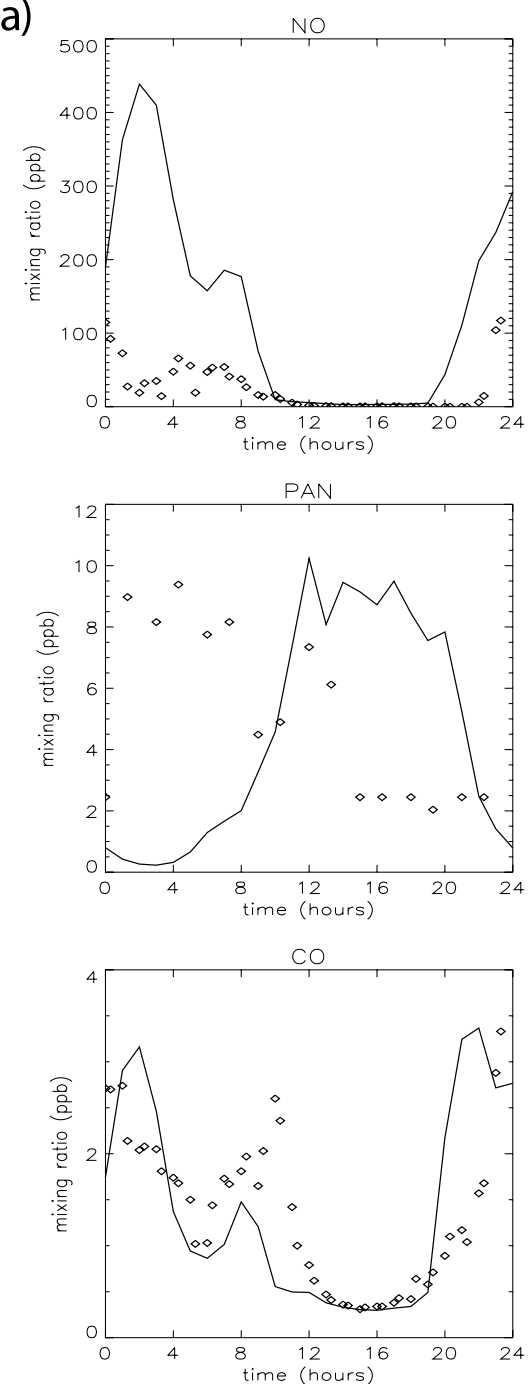
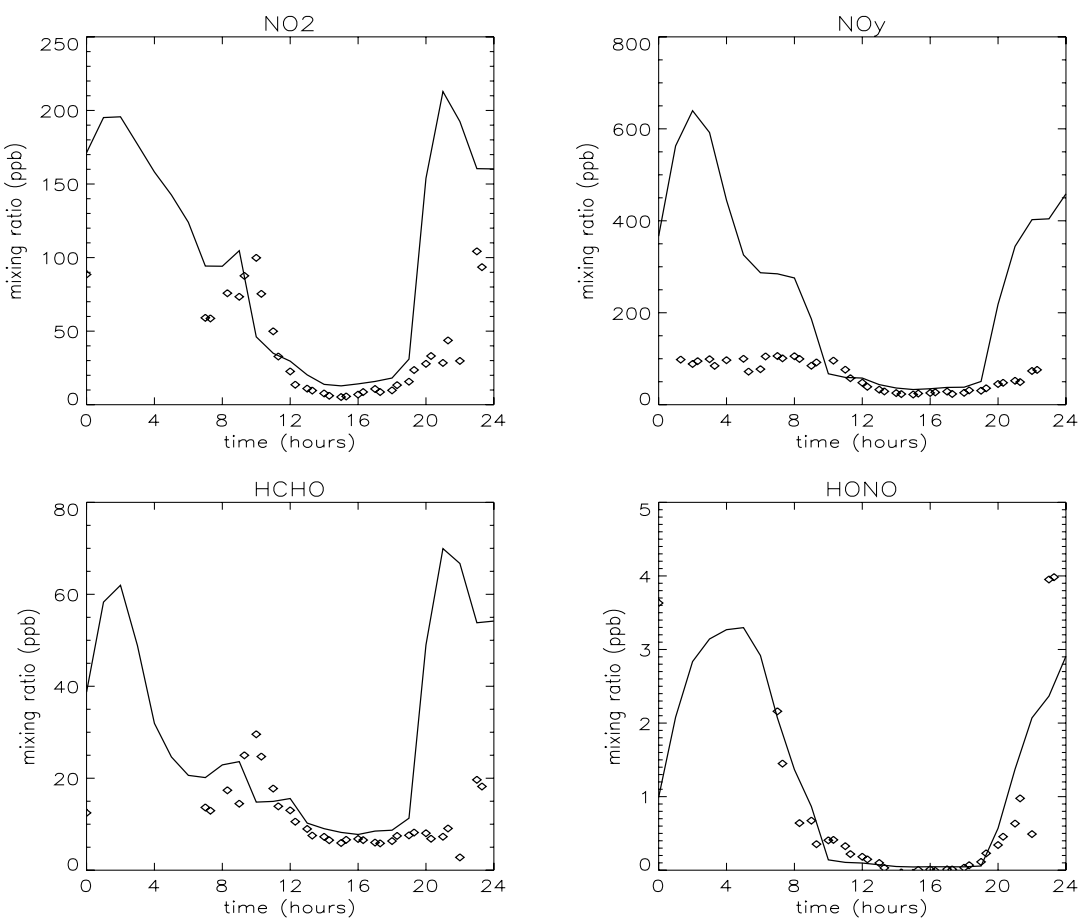

Figure 9. Comparison between the simulation and the measurements for different species related to the $\mathrm{O}_{3}$ aerosol formation (a) in Bresso and (b) in Verzago.

model domain the $\mathrm{CO}$ reactivity is very small compared to the total VOC reactivity (only a few percent), this bias will be small. The overestimation of the $\mathrm{SO}_{2}$ emission will enhance the $\mathrm{HO}_{2} / \mathrm{OH}$ ratio owing to the reaction $\mathrm{SO}_{2}+$ $\mathrm{OH}=\mathrm{SO}_{3}+\mathrm{HO}_{2}$. This enhances the oxidation of $\mathrm{NO}$ to $\mathrm{NO}_{2}$ and therefore also the $\mathrm{O}_{3}$ production. Simulation with the model in the 1-D version showed that the effect is small.

\section{VOC/NO ${ }_{x}$ Sensitivity Study}

[41] The sensitivity of the Milan photooxidant plume to $\mathrm{NO}_{x}$ and VOC precursors has already been the subject of extensive study [Staffelbach et al., 1997a, 1997b; Prévôt et al., 1997]. This study offers new insights in two major areas: results from an analysis based on three-dimensional simulations for the Milan area, and results from an updated measurement set that includes aerosols. The subsequent analysis will also show the impact of including heterogeneous chemistry on model predictions. It will also include the use of measurement-based indicators as a way to improve confidence in model $\mathrm{NO}_{x}$-VOC predictions.

\subsection{Model Setup for the Scenarios}

[42] Sensitivity studies have been performed by reducing anthropogenic VOC and $\mathrm{NO}_{x}$ emissions by $35 \%$ in the domain, keeping the same initial and boundary conditions. The analysis investigates therefore only the sensitivity to a local reduction of the emissions. This is a typical situation that a regional government has to deal with. The choice of $35 \%$ is an arbitrary one, but goes along with possible reduction scenarios that can be reached within a few years from now. All runs were performed with and without aerosols to evaluate the impact of the heterogeneous chemistry on $\mathrm{NO}_{x}$-VOC indicators.

\subsection{Model Predictions}

[43] Figure 10 shows the predicted changes in surface $\mathrm{O}_{3}$ concentrations at $1600 \mathrm{LT}$ resulting from $35 \%$ reductions in VOC or $\mathrm{NO}_{x}$ emissions throughout the model domain. 
b)
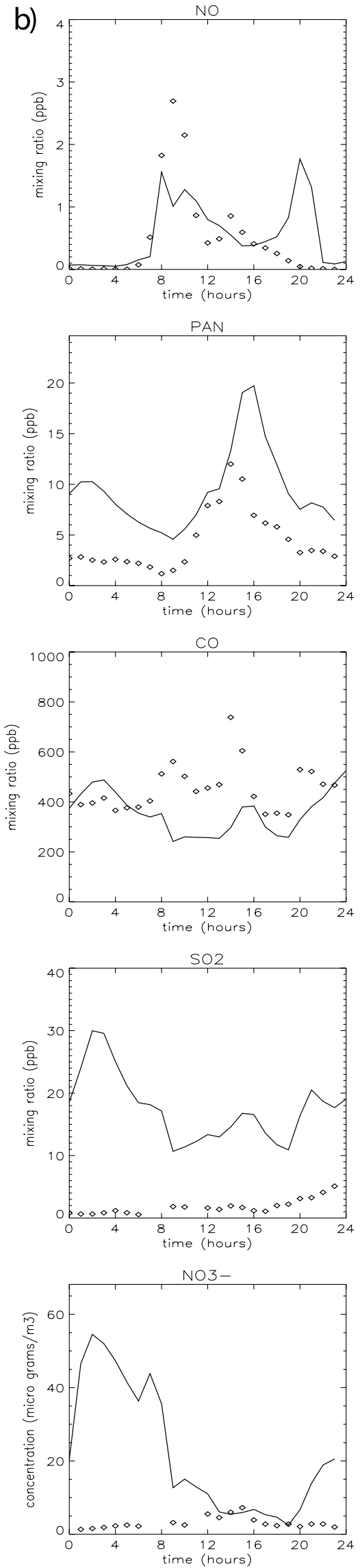
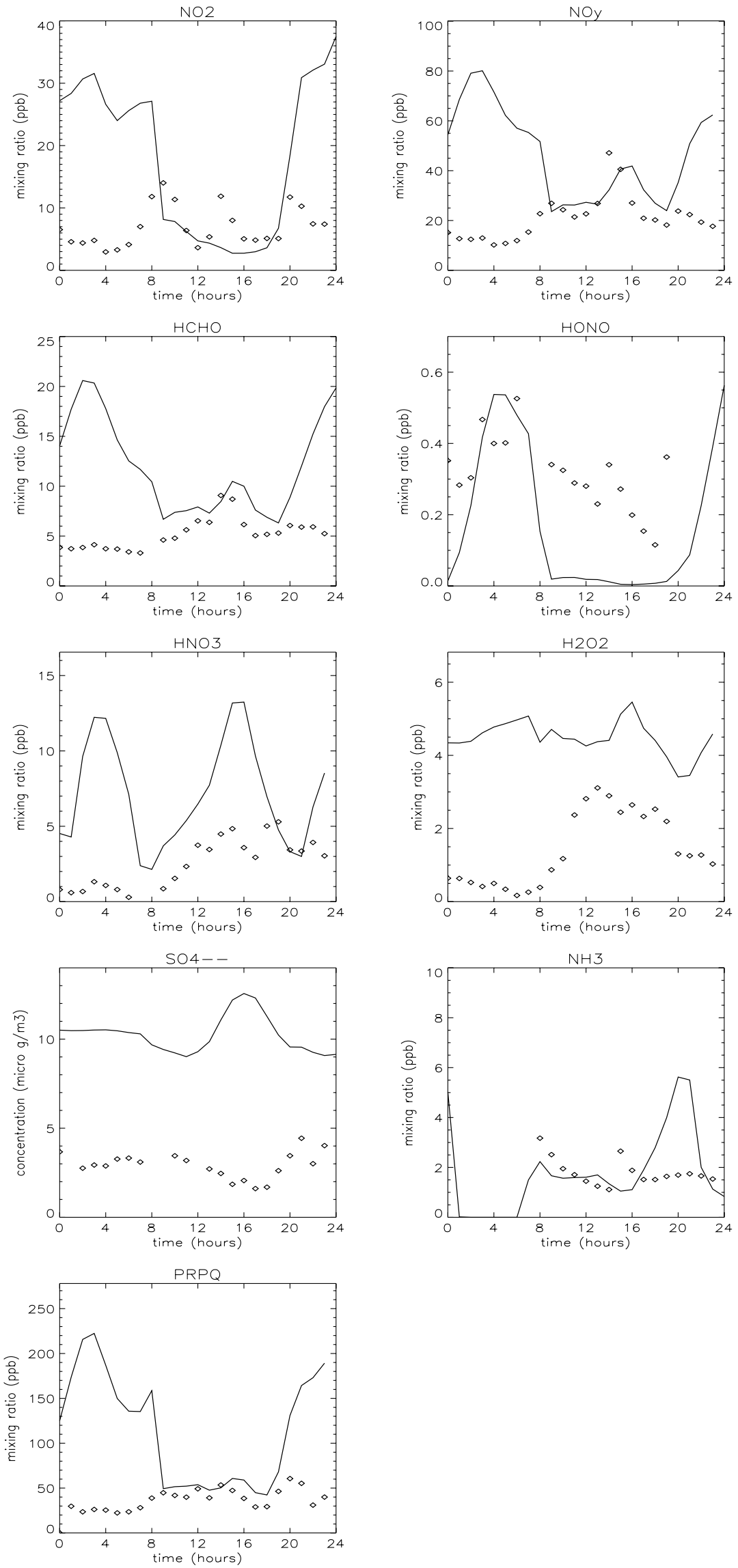

Figure 9. (continued) 
Table 2. Different Pollutant Concentrations in the Simulated and the Measured Plume at Verzago ${ }^{\text {a }}$

\begin{tabular}{lccc}
\hline \multicolumn{1}{c}{ Species } & Measured & Simulated & Simulated Peak $^{\mathrm{b}}$ \\
\hline $\mathrm{O}_{3}$ & $190 \mathrm{ppbV}$ & $183 \mathrm{ppbV}$ & yes \\
$\mathrm{NO}_{y}$ & $47 \mathrm{ppbV}$ & $41 \mathrm{ppbV}$ & yes \\
$\mathrm{NO}_{2}$ & $12 \mathrm{ppbV}$ & $2.7 \mathrm{ppbV}$ & no \\
$\mathrm{NO}$ & $0.9 \mathrm{ppbV}$ & $0.4 \mathrm{ppbV}$ & no \\
$\mathrm{HNO}$ & $5 \mathrm{ppbV}$ & $13 \mathrm{ppbV}$ & yes \\
$\mathrm{PAN}^{\mathrm{c}}$ & $12 \mathrm{ppbV}$ & $20 \mathrm{ppbV}$ & yes \\
$\mathrm{HONO}$ & $0.34 \mathrm{ppbV}$ & $0.004 \mathrm{ppbV}$ & no \\
$\mathrm{PRPQ}^{\mathrm{d}}$ & $53 \mathrm{ppbC}$ & $59 \mathrm{ppbC}$ & yes \\
$\mathrm{MEK}^{\mathrm{e}}$ & $13.5 \mathrm{ppbV}$ & $18.7 \mathrm{ppbV}$ & yes \\
$\mathrm{HCHO}$ & $9 \mathrm{ppbV}$ & $10 \mathrm{ppbV}$ & yes \\
$\mathrm{H}_{2} \mathrm{O}_{2}$ & $2.9 \mathrm{ppbV}$ & $5.4 \mathrm{ppbV}$ & yes \\
$\mathrm{NO}_{3}{ }^{-}$ & $2.4 \mathrm{ppbV}$ & $2.7 \mathrm{ppbV}$ & yes \\
$\mathrm{CO}$ & $738 \mathrm{ppbV}$ & $383 \mathrm{ppbV}$ & yes \\
$\mathrm{O}_{3} / \mathrm{NO}_{\mathrm{y}}$ & 4 & 4.4 & \\
$\mathrm{O}_{3} / \mathrm{NO}_{\mathrm{z}}$ & 5.5 & 4.7 & \\
$\mathrm{O}_{3} /\left(\mathrm{HNO}_{3}+\mathrm{NO}_{3}{ }^{-}\right)$ & 27.7 & 11.5 & \\
$\mathrm{H}_{2} \mathrm{O}_{2} /\left(\mathrm{HNO}_{3}+\mathrm{NO}_{3}{ }^{-}\right)$ & 0.42 & 0.34 & \\
\hline
\end{tabular}

${ }^{\mathrm{a}}$ The table gives the highest values measured and simulated in Verzago during the afternoon of 13 May (between 1400 LT and 1600 LT) for several pollutants and for the Sillman indicator ratios. For all these species an increase in the concentration has been measured around 1400 LT at this location, owing to the arrival of the Milan plume.

${ }^{\mathrm{b}}$ This column indicates whether a similar enhancement has been simulated.

${ }^{\mathrm{c}}$ Peroxyacetyl nitrate.

${ }^{\mathrm{d}}$ Propane-equivalent carbon.

${ }^{\mathrm{e}}$ Methylethylketone.

Several features are apparent in this figure. The Milan plume is often (though not always) characterized by sensitivity to VOC in the model, while the surrounding region (including the upwind part of Milan) is characterized by sensitivity to $\mathrm{NO}_{x}$. Within the Milan urban center, $\mathrm{NO}_{x}$ reductions are predicted to increase $\mathrm{O}_{3}$ by as much as 20 ppb during the morning and early afternoon (until 1400 LT). Until 1400 LT the Milan plume (including the region of maximum $\mathrm{O}_{3}$ extending $50 \mathrm{~km}$ north of the city, and side plumes to Bergamo and Varese) is essentially VOC sensitive. By $1600 \mathrm{LT}$, reduced $\mathrm{NO}_{x}$ emissions cause lower $\mathrm{O}_{3}$ everywhere, even in the Milan urban center. Also, by 1600 LT the region of greater sensitivity to VOC has shrunk to an ellipsoid with a width of $10 \mathrm{~km}$, including the Milan urban center and extending approximately $35 \mathrm{~km}$ downwind of Milan. Reduced VOC has its greatest impact on $\mathrm{O}_{3}(41 \mathrm{ppb})$ between Seregno and Verzago, around $30 \mathrm{~km}$ north of Milan. At this location (corresponding to $183 \mathrm{ppb} \mathrm{O}_{3}$ in the model base case), the predicted impact of reduced VOC is much larger than the impact of reduced $\mathrm{NO}_{x}(17 \mathrm{ppb}$ lower $\mathrm{O}_{3}$ ). The impact of $\mathrm{NO}_{x}$ reductions increases as one moves further downwind, with the greatest impact (24 ppb) occurring around $40 \mathrm{~km}$ north of Milan.

[44] Homogeneous and heterogeneous runs show only minor differences in the $\mathrm{O}_{3}$ concentrations and also in predicted $\mathrm{NO}_{x}-\mathrm{VOC}$ sensitivity. The only reaction included here that couples aerosols with $\mathrm{O}_{3}$ is the gas phase reaction of $\mathrm{HNO}_{3}$ with $\mathrm{OH}$ that produces $\mathrm{NO}_{2}$. By converting some $\mathrm{HNO}_{3}$ to aerosol nitrate, aerosol reactions can lower this source of $\mathrm{NO}_{2}$. This causes slightly lower $\mathrm{O}_{3}$ in some parts of the model. We have not included other possible impacts of aerosols, some of which may have significant impacts (e.g., aerosol impact on photolysis rates).

\section{3. $\mathrm{NO}_{x}$-VOC Indicators}

[45] Sillman [1995] has proposed the idea that the ratio of certain trace gas concentrations such as $\mathrm{H}_{2} \mathrm{O}_{2} / \mathrm{HNO}_{3}$ and $\mathrm{O}_{3} / \mathrm{NO}_{z}$ (where $\mathrm{NO}_{z}$ represents $\mathrm{NO}_{x}$ reaction products, $\mathrm{NO}_{y}-\mathrm{NO}_{x}$ ) can be used to distinguish between $\mathrm{NO}_{x}$-sensitive and VOC-sensitive $\mathrm{O}_{3}$ regimes. In a series of publications [Sillman, 1995, 1999; Sillman et al., 1998; Tonnesen and Dennis, 2000a, 2000b] it was reported that VOCsensitive conditions in models corresponded to low model values of $\mathrm{H}_{2} \mathrm{O}_{2} / \mathrm{HNO}_{3}$ (below 0.3), $\mathrm{O}_{3} / \mathrm{NO}_{y}$ (below 7), and $\mathrm{O}_{3} / \mathrm{NO}_{z}$ (below 9). Some contrary results have been reported [Lu and Chang, 1998; Chock et al., 1999], suggesting that the predicted indicator correlation may not apply for all conditions. Also, a major omission of previous work has been the failure to include heterogeneous chemistry. The indicator ratios proposed by Sillman et al. [1998] all involve $\mathrm{HNO}_{3}$ (either directly or as a component of $\mathrm{NO}_{y}$ and $\mathrm{NO}_{z}$ ) and are therefore likely to be affected by the production of aerosol nitrate. Heterogeneous chemistry also affects the lifetime of reactive nitrogen by converting $\mathrm{HNO}_{3}$ to longer-lived aerosol nitrate [Meng et al., 1997]. This aerosol effect has not been included in previous studies.

[46] Here, we seek to evaluate (1) whether the indicators proposed by Sillman are applicable to Milan, which may have very different chemistry from the conditions where indicator correlations have previously been examined and (2) how the proposed indicators are affected by heterogeneous chemistry.

[47] Figure 11 shows the correlation between predicted $\mathrm{NO}_{x}$-VOC sensitivity and the indicator ratios $\mathrm{H}_{2} \mathrm{O}_{2} / \mathrm{HNO}_{3}$ in the model for Milan. This correlation is analogous to similar correlations from models without aerosol chemistry shown by Sillman [1995, 1999] and Sillman et al. [1998]. It can be seen from the figure that VOC-sensitive locations generally correspond to low model values of this ratio, and $\mathrm{NO}_{x}$-sensitive locations correspond to high ratio values. However, there are a number of outliers, locations that have high values for $\mathrm{H}_{2} \mathrm{O}_{2} / \mathrm{HNO}_{3}$ while showing greater sensitivity to $\mathrm{VOC}$ than to $\mathrm{NO}_{x}$. These outliers apparently occur in locations where large amounts of $\mathrm{HNO}_{3}$ have been converted to aerosol nitrate. These outliers can be eliminated by using the sum of nitric acid and aerosol nitrate, $\left(\mathrm{HNO}_{3}+\mathrm{NO}_{3}{ }^{-}\right)$, in place of $\mathrm{HNO}_{3}$ in the indicator ratio. As shown in Figure $11 \mathrm{~b}$, the modified ratio $\mathrm{H}_{2} \mathrm{O}_{2} /\left(\mathrm{HNO}_{3}+\right.$ $\mathrm{NO}_{3}^{-}$) correlates with model $\mathrm{NO}_{x}-\mathrm{VOC}$ sensitivity, with fewer outliers.

[48] The correspondence between $\mathrm{NO}_{x}$-VOC sensitivity and indicator values in models can be expressed quantitatively using methods described by Sillman et al. [1998] and Sillman [1999]. The ranges of indicator values associated with VOC-sensitive model locations and with $\mathrm{NO}_{x}$-sensitive locations are expressed as percentile distributions. These distributions are summarized by using the 5th, 50th and 95th percentile values associated with $\mathrm{NO}_{x}$-sensitive and VOC-sensitive locations. If a $\mathrm{NO}_{x}$-VOC indicator is useful, the median value for VOC-sensitive locations must be significantly lower than the median value for $\mathrm{NO}_{x}$-sensitive locations, and the 95th percentile value for VOC-sensitive locations must be equal to or less than the 5 th percentile value for $\mathrm{NO}_{x}$-sensitive locations. If these conditions hold, it means that nearly all the VOC-sensitive locations in the model have lower indicator values than the $\mathrm{NO}_{x}$-sensitive 

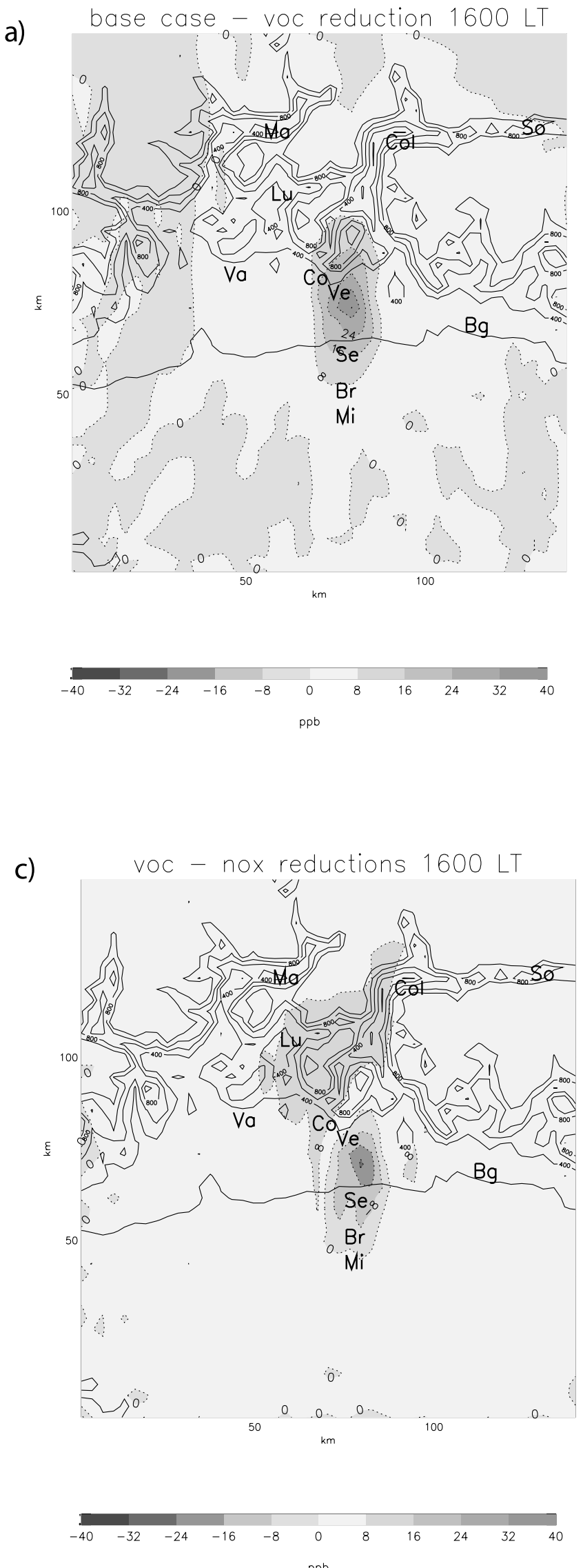
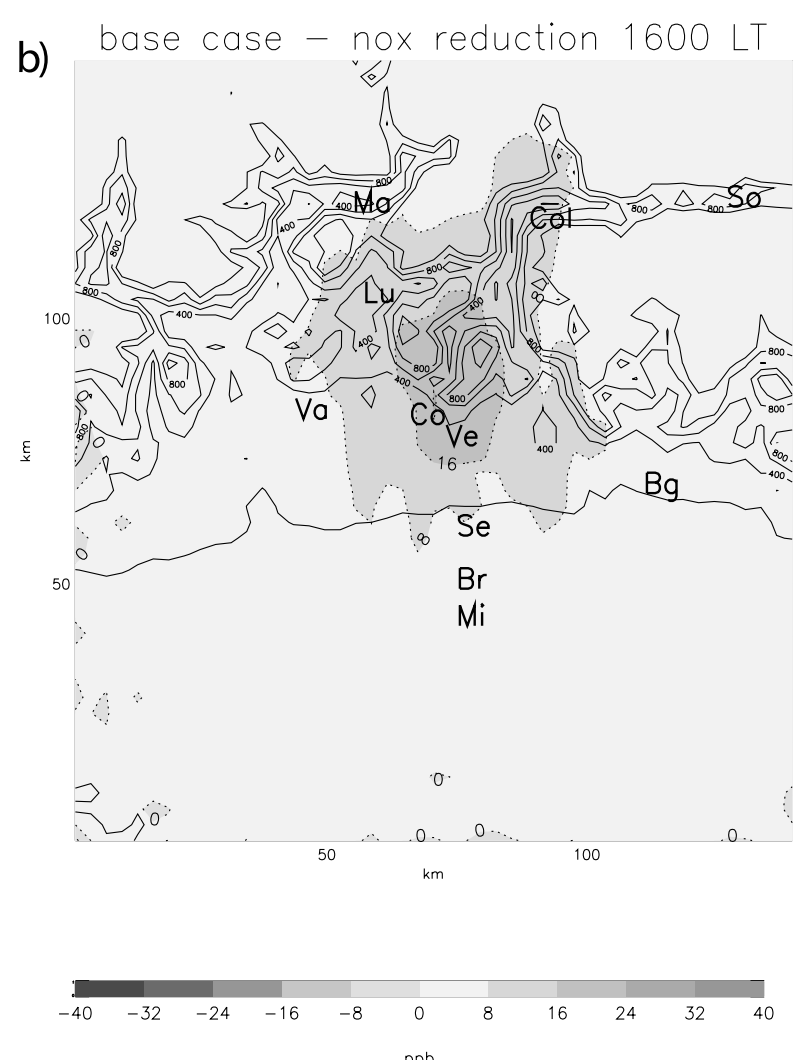

$\mathrm{ppb}$ 

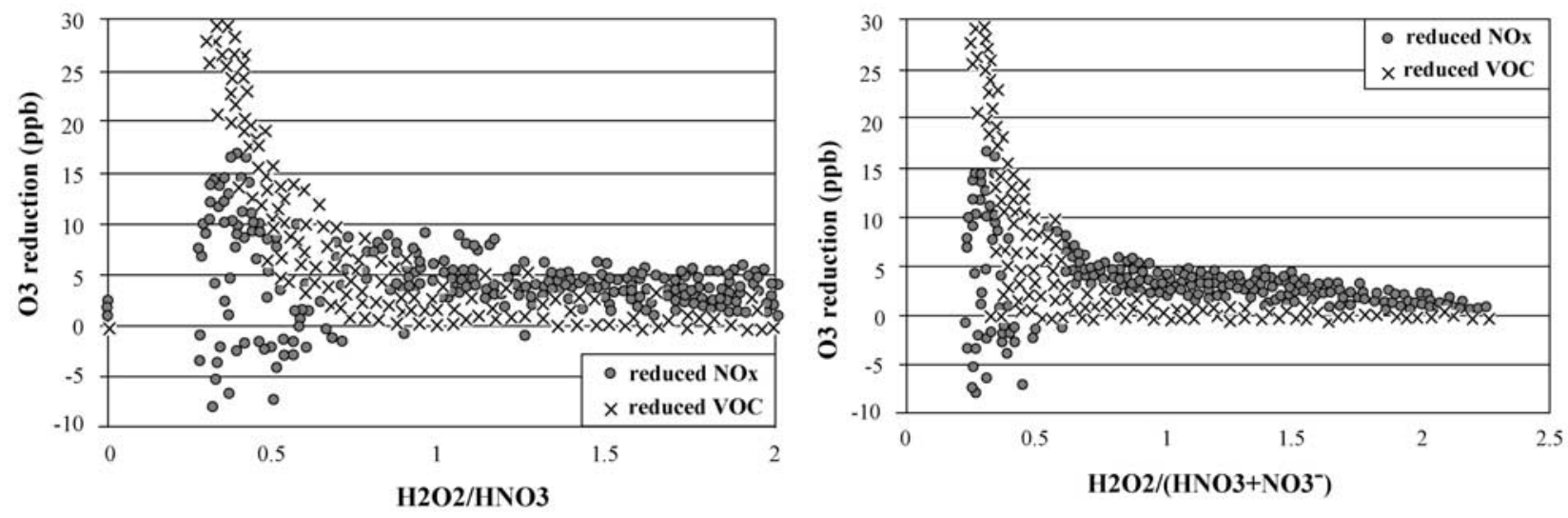

Figure 11. Indicators for homogeneous and aerosol runs: Predicted reduction in $\mathrm{O}_{3}$ (ppb) at 1600 LT resulting from a 35\% reduction in VOC emissions (crosses) and from a 35\% reduction in $\mathrm{NO}_{x}$ (circles) at each model location. The predicted reductions are plotted against model values for indicator ratios: (a) $\mathrm{H}_{2} \mathrm{O}_{2} / \mathrm{HNO}_{3}$ and (b) $\mathrm{H}_{2} \mathrm{O}_{2} /\left(\mathrm{HNO}_{3}+\mathrm{NO}_{3}^{-}\right)$, at the same location.

model locations. The 95th percentile VOC-sensitive value and the 5 th percentile $\mathrm{NO}_{x}$-sensitive value mark the transition from VOC-sensitive to $\mathrm{NO}_{x}$-sensitive chemistry. For this analysis we will define model locations as $\mathrm{NO}_{x}$ sensitive whenever a $35 \%$ reduction in $\mathrm{NO}_{x}$ emissions results in lower $\mathrm{O}_{3}$ at the specified time than $\mathrm{O}_{3}$ in either the model base case and in the scenario with reduced VOC, by at least 5 ppb. VOC-sensitive locations are defined similarly.

[49] Results of this analysis are shown in Table 3 for the ratios $\mathrm{O}_{3} / \mathrm{NO}_{y}, \mathrm{O}_{3} / \mathrm{NO}_{z}, \mathrm{O}_{3} / \mathrm{HNO}_{3}$, and $\mathrm{H}_{2} \mathrm{O}_{2} / \mathrm{HNO}_{3}$, and for equivalent ratios with aerosol nitrate included. For comparison, results are shown from a previous study of indicators the northeastern United States [Sillman, 1995] and in Nashville [Sillman et al., 1998], on the basis of simulations with only gas phase chemistry.

[50] Results show that the ratios $\mathrm{O}_{3} / \mathrm{NO}_{y}$ and $\mathrm{H}_{2} \mathrm{O}_{2} / \mathrm{HNO}_{3}$ are both successful for separating $\mathrm{NO}_{x}$-sensitive and VOCsensitive locations in the model for Milan. $\mathrm{O}_{3} / \mathrm{NO}_{z}$ and $\mathrm{O}_{3} / \mathrm{HNO}_{3}$ are somewhat less successful, because there is significant overlap of values associated with $\mathrm{NO}_{x}$-sensitive and VOC-sensitive locations. The inclusion of aerosol nitrate (by including it as part of $\mathrm{NO}_{y}$ and $\mathrm{NO}_{z}$ and replacing $\mathrm{HNO}_{3}$ by the sum $\mathrm{HNO}_{3}+\mathrm{NO}_{3}^{-}$) has relatively little impact on the indicator correlation as summarized in Table 3. However, results from Figure 11 suggest that indicator ratios should be modified to include aerosol nitrate.

[51] In comparison with previous results, it appears that the transition from $\mathrm{NO}_{x}$ - to VOC-sensitive chemistry occurs at slightly different indicator values in the model for Milan. The transition value for $\mathrm{O}_{3} / \mathrm{NO}_{y}$ is slightly lower then in previous cases ( 5 versus $6-7$ ), suggesting that $\mathrm{NO}_{x}$-sensitive chemistry can occur with lower $\mathrm{O}_{3} / \mathrm{NO}_{y}$. The transition values for $\mathrm{O}_{3} / \mathrm{HNO}_{3}$ and $\mathrm{H}_{2} \mathrm{O}_{2} / \mathrm{HNO}_{3}$ are both somewhat higher then in previous cases. These variations in transition values may reflect different photochemical behavior in Milan, or they may be caused by differences in model formulation and chemistry, or boundary conditions. However, the comparison between the measurements and the model results suggests that the TVM model formulation tends to overestimate $\mathrm{HNO}_{3}$ concentrations (see section 4.2.2) and therefore to underestimate the values for $\mathrm{O}_{3} / \mathrm{HNO}_{3}$ and $\mathrm{H}_{2} \mathrm{O}_{2} / \mathrm{HNO}_{3}$. Consequently, the TVM model probably underestimates the transition values and the deviation from previous transition values may be even greater. The difference may also be related to the relatively high concentrations of organic nitrates in Milan, compared to previous investigations of indicator ratios.

\section{Discussion}

[52] In interpreting these results, there are two major areas of uncertainty: direct model-measurement comparisons and accuracy of model $\mathrm{NO}_{x}$-VOC predictions. Results from Table 3 suggest that the current simulation reproduces many features of the Milan plume during this event. $\mathrm{O}_{3}$, total reactive nitrogen, $\mathrm{HCHO}$, and summed VOC (expressed as propene-equivalent carbon) all show good agreement between model and measurements. The major areas of disagreement include the following: (1) the model underestimates the ratio $\mathrm{NO}_{z} / \mathrm{NO}_{y}$, suggesting that the rate of photochemical processing may be too high, and (2) the model overestimates both $\mathrm{H}_{2} \mathrm{O}_{2}$ and $\mathrm{HNO}_{3}$ in comparison with measurements.

[53] The overestimation for $\mathrm{H}_{2} \mathrm{O}_{2}$ and $\mathrm{HNO}_{3}$ may be due to dry deposition (see discussion by Sillman et al. [1998]) and may be exacerbated by the treatment of photochemically active species at the model boundary. As described

Figure 10. (opposite) Predicted change in surface $\mathrm{O}_{3}(\mathrm{ppb})$ at 1600 LT resulting from a 35\% reduction in anthropogenic VOC emissions (Figure 10a) and from a 35\% reduction in $\mathrm{NO}_{x}$ emissions (Figure 10b). Figure 10c shows the difference between the reduced-VOC and reduced- $\mathrm{NO}_{x}$ runs, with positive values corresponding to locations with lower $\mathrm{O}_{3}$ in the run with reduced $\mathrm{NO}_{x}$. Results are from simulations that include aerosols. See color version of this figure at back of this issue. 
Table 3. Distribution of Photochemical Indicator Values for $\mathrm{NO}_{x^{-}}$and VOC-Sensitive Chemistry ${ }^{\mathrm{a}}$

\begin{tabular}{|c|c|c|c|c|c|c|c|}
\hline \multirow[b]{2}{*}{ Indicator } & \multirow[b]{2}{*}{ Location } & \multicolumn{3}{|c|}{ VOC-Sensitive Locations } & \multicolumn{3}{|c|}{$\mathrm{NO}_{x}$-Sensitive Locations } \\
\hline & & 5th Percentile & 50th Percentile & 95th Percentile & 5th Percentile & 50th Percentile & 95th Percentile \\
\hline $\mathrm{O}_{3} /\left(\mathrm{NO}_{v}+\mathrm{NO}_{3}^{-}\right)$ & Milan & 3.5 & 4.1 & 5.2 & 5.1 & 6.9 & 9.2 \\
\hline $\mathrm{O}_{3} / \mathrm{NO}_{y} * \mathrm{~b}$ & Milan & 3.6 & 4.3 & 5.6 & 5.7 & 8.2 & 11.1 \\
\hline $\mathrm{O}_{3} / \mathrm{NO}_{y}$ & USA northeast & 5.0 & 5.4 & 6.5 & 8.2 & 12.7 & 18. \\
\hline $\mathrm{O}_{3} / \mathrm{NO}_{y}$ & Nashville & 2.2 & 3.6 & 5.6 & 7.1 & 10.8 & 13. \\
\hline $\mathrm{O}_{3} /\left(\mathrm{NO}_{z}+\mathrm{NO}_{3}^{-}\right)$ & Milan & 4.6 & 5.7 & 7.1 & 5.6 & 7.6 & 10.6 \\
\hline $\mathrm{O}_{3} / \mathrm{NO}_{z} * \mathrm{~b}$ & Milan & 4.9 & 6.0 & 7.4 & 6.2 & 9.4 & 12.5 \\
\hline $\mathrm{O}_{3} / \mathrm{NO}_{z}$ & USA northeast & 6.7 & 7.1 & 7.7 & 9.7 & 14.4 & 20. \\
\hline $\mathrm{O}_{3} / \mathrm{NO}_{z}$ & Nashville & 5.3 & 6.3 & 7.3 & 8.4 & 12.4 & 13. \\
\hline $\mathrm{O}_{3} /\left(\mathrm{HNO}_{3}+\mathrm{NO}_{3}^{-}\right)$ & Milan & 10. & 13. & 16. & 14. & 18. & 27. \\
\hline $\mathrm{O}_{3} / \mathrm{HNO}_{3}$ & Milan & 12 & 15. & 18. & 17. & 29. & 78. \\
\hline $\mathrm{O}_{3} / \mathrm{HNO}_{3}$ & USA northeast & 10. & 11. & 16. & 17. & 27. & 42. \\
\hline $\mathrm{O}_{3} / \mathrm{HNO}_{3}$ & Nashville & 6. & 8. & 9. & 12. & 19. & 21. \\
\hline $\mathrm{H}_{2} \mathrm{O}_{2} /\left(\mathrm{NO}_{3}+\mathrm{NO}_{3}^{-}\right)$ & Milan & 0.23 & 0.32 & 0.50 & 0.46 & 0.67 & 1.17 \\
\hline $\mathrm{H}_{2} \mathrm{O}_{2} / \mathrm{HNO}_{3}$ & Milan & 0.26 & 0.37 & 0.56 & 0.59 & 1.12 & 2.75 \\
\hline $\mathrm{H}_{2} \mathrm{O}_{2} / \mathrm{HNO}_{3}$ & USA northeast & 0.22 & 0.33 & 0.40 & 0.68 & 1.58 & 3.1 \\
\hline $\mathrm{H}_{2} \mathrm{O}_{2} / \mathrm{HNO}_{3}$ & Nashville & 0.11 & 0.18 & 0.23 & 0.30 & 0.64 & 0.82 \\
\hline
\end{tabular}

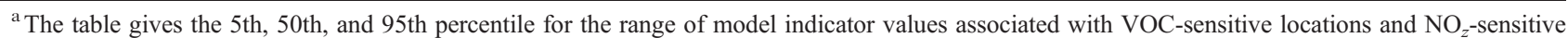
locations in simulations for Milan (1600 LT). Previous results from the northeastern United States [Sillman, 1995] and Nashville [Sillman et al., 1998] are shown for comparison.

${ }^{\mathrm{b}} \mathrm{NO}_{y}^{*}$ and $\mathrm{NO}_{z}^{*}$ are used to denote the sum of reactive nitrogen and $\mathrm{NO}_{x}$ reaction products that explicitly exclude aerosol $\mathrm{NO}_{3}^{-}$. When $\mathrm{NO}_{3}^{-}$is included in the sum, it has been written explicitly.

above, conditions along the upwind boundary were established by a 1-D model calculation, using average Po Valley emission characteristics for an 8 day period. This calculation is important because the inflow of $\mathrm{O}_{3}$ to the Milan area has already been augmented by photochemical production in the Po Valley, and the concentration of other secondary species, including $\mathrm{H}_{2} \mathrm{O}_{2}$ and $\mathrm{HNO}_{3}$, should also be affected by this upwind photochemical activity. Model concentrations of $\mathrm{H}_{2} \mathrm{O}_{2}$ and $\mathrm{HNO}_{3}$ are sensitive to the assumed deposition rate in this 1-D calculation.

[54] The model $\mathrm{NO}_{x}$-VOC sensitivity described in section 5 shows many features that are typical of predicted $\mathrm{NO}_{x}$-VOC sensitivity in three-dimensional models (see, for example, Sillman [1999] for a summary). These include greater sensitivity to $\mathrm{VOC}$ in the urban plume and greater sensitivity to $\mathrm{NO}_{x}$ in the surrounding rural region, greater sensitivity to $\mathrm{VOC}$ close to the urban center and greater sensitivity to $\mathrm{NO}_{x}$ further downwind, and greater benefit from reduced $\mathrm{NO}_{x}$ later in the day. These features are also generally consistent with previous results for the Milan plume [Prévôt et al., 1997; Staffelbach et al., 1997a, 1997b]. Uncertainties in model formulation and assumptions are unlikely to change these major features. However, the impact of model uncertainties is most likely to affect VOC-NO $\mathrm{N}_{x}$ sensitivity predictions in those regions of the Milan urban plume that are close to the "transition" from VOC-sensitive chemistry to $\mathrm{NO}_{x}$-sensitive chemistry. These regions often coincide with peak $\mathrm{O}_{3}$ in the plume.

[55] The largest likely source of uncertainty is associated with emission rates for $\mathrm{NO}_{x}$ and VOC (including anthropogenic VOC) and the reactivity of the emitted VOC. Previous results have shown that the extent of VOCsensitive chemistry in urban plumes can change significantly if emission rates are changed by as little as $25 \%$ (see summary in the work by Sillman [1999]). In this context it is significant that model results compare well with measured values for $\mathrm{NO}_{y}$ and VOC.

[56] Predicted $\mathrm{NO}_{x}$-VOC sensitivity may also be affected by the rate of vertical mixing during the morning and by photolysis rates. Although not tested here, less rapid vertical mixing during the morning hours can be expected to slow the rate of photochemical aging in the urban plume, and thus might extend the VOC-sensitive region in the urban plume [e.g., Milford et al., 1994; Spirig et al., 2002]. Lower photolysis rates would also tend to extend the VOC-sensitive region in general [Kleinman, 1994] and in the Milan plume in particular [Staffelbach et al., 1997b]. These might be important because enhanced aerosol concentrations may cause photolysis rates to be lower than the clear-sky values used here in the model [e.g., Dickerson et al., 1997; Jacobson, 1999]. Here, measured $j_{\mathrm{NO} 2}$ at Verzago was found to decrease by $10 \%$ during the passage of the Milan plume [Thielmann et al., 2002].

[57] The measured indicator ratios (see Table 3) provide evidence in support of the model prediction that VOCsensitive conditions occur for part of the Milan plume, at least as far as Verzago. The measured $\mathrm{O}_{3} / \mathrm{NO}_{y}, \mathrm{O}_{3} / \mathrm{NO}_{z}$, $\mathrm{O}_{3} /\left(\mathrm{HNO}_{3}+\mathrm{NO}_{3}^{-}\right)$, and $\mathrm{H}_{2} \mathrm{O}_{2} /\left(\mathrm{HNO}_{3}+\mathrm{NO}_{3}^{-}\right)$all have values that are associated with VOC-sensitive conditions in models, including the model used here. The values of these ratios also do not differ greatly from the model values. There is some uncertainty in this interpretation owing to model-measurement discrepancies for $\mathrm{H}_{2} \mathrm{O}_{2}$ and $\mathrm{HNO}_{3}$ as discussed above, and owing to the uncertain composition of $\mathrm{NO}_{y}$. The apparent VOC-sensitive conditions at Verzago do not preclude a switch to $\mathrm{NO}_{x}$-sensitive chemistry further downwind, as predicted by the model.

[58] Spirig et al. [2002] found that for 13 May at Verzago, the instantaneous $\mathrm{O}_{3}$ production is $\mathrm{VOC}$ sensitive during the passage of the Milan plume. The $\mathrm{NO}_{x}$-VOC sensitivity of the instantaneous $\mathrm{O}_{3}$ production is not necessarily the same as the $\mathrm{NO}_{x}$-VOC sensitivity associated with $\mathrm{O}_{3}$ concentrations, because the latter is affected by upwind conditions as $\mathrm{O}_{3}$ is produced. This issue is discussed in greater detail by Kleinman et al. [2000].

[59] It is also useful to compare the results shown here with results from previous studies of the Milan plume reported by Prévôt et al. [1997] and Staffelbach et al. [1997a, 1997b]. Prévôt et al. reported similar values of 
peak $\mathrm{O}_{3}(170 \mathrm{ppb}), \mathrm{NO}_{2}$ (peak afternoon value $20 \mathrm{ppb}$ ) and $\mathrm{H}_{2} \mathrm{O}_{2}(2-3 \mathrm{ppb})$, but they reported much lower values of $\mathrm{NO}_{z}$ (peak value $12 \mathrm{ppb}$ ) and higher values for the ratio $\mathrm{O}_{3} / \mathrm{NO}_{z}$ (13 or higher). Staffelbach et al. also reported low values of $\mathrm{NO}_{z}(<10 \mathrm{ppb}), \mathrm{HNO}_{3}(<4 \mathrm{ppb})$ and higher $\mathrm{O}_{3} / \mathrm{NO}_{\mathrm{z}}(>13)$. The three papers refer to field data that have been collected later in the summer (July and August) compared to the PIPAPO study. The results that Staffelbach et al. [1997a] reported stem from a ground station located approximately $15 \mathrm{~km}$ northwest of Verzago in an area with high biogenic emissions. If this ratio is interpreted as a $\mathrm{NO}_{x^{-}}$ VOC indicator, then the contrast with previous results suggests that the event reported here has different chemistry, with greater sensitivity to VOC than found previously. One reason could be the lower level of reactive VOC present during the first IOP of the PIPAPO study.

[60] In conclusion, the model predicts that both $\mathrm{NO}_{x^{-}}$ sensitive and VOC-sensitive conditions occur at different stages of the Milan plume. The measured indicator ratios reported here provide evidence (consistent with model results) that VOC-sensitive conditions occur for at least part of the plume, while previous measurements [Staffelbach et al., 1997b; Prévôt et al., 1997] provided evidence that mixed and $\mathrm{NO}_{x}$-sensitive conditions also occur in parts of the Milan plume. Dommen et al. [2002] derived the sensitivity of the instantaneous $\mathrm{O}_{3}$ production from airplane measurements. These analyses show a transition from $\mathrm{NO}_{x}$ to VOC sensitivity crossing the Milano plume between Seregno and Verzago on 13 May from west to east in the afternoon. The analyses of the other flight data confirm that the core of the Milan plume is VOC sensitive.

\section{Conclusions}

[61] The simulation of the very pronounced $\mathrm{O}_{3}$ episode of 13 May 1998 in the greater Milan area with the 3-D Eulerian model TVM-LCC yielded very satisfactory results. Both the spatial and the temporal variability of the simulated $\mathrm{O}_{3}$ concentrations correspond reasonably well to the measured values. The comparison with a series of other trace species relevant for the $\mathrm{O}_{3}$ formation showed differences that can be explained by the characteristics of the measurements, the accuracy of the model input data, and the weaknesses of the model formulation. In turn, these deviations do not affect to a large extent the sensitivity of the $\mathrm{O}_{3}$ formation with respect to $\mathrm{VOC}$ and $\mathrm{NO}_{x}$ sensitivity.

[62] The sensitivity runs with $35 \%$ reduced $\mathrm{NO}_{x}$ and VOC emissions showed that the indicator concept could be applied to the Milan area, but that it is necessary to modify the indicator ratios to include aerosol nitrate. Aerosol nitrate must be included in the reactive nitrogen sum $\left(\mathrm{NO}_{y}\right)$, and the sum $\left(\mathrm{HNO}_{3}+\mathrm{NO}_{3}^{-}\right)$must be used in place of $\mathrm{HNO}_{3}$ in the indicator ratios identified by Sillman [1995] and Sillman et al. [1998]. The core of the Milan plume has an extension of only $10 \mathrm{~km}$ in length and $15 \mathrm{~km}$ in width at 1600 LT. Highest $\mathrm{O}_{3}$ values appear at the transition from VOC to $\mathrm{NO}_{x}$ sensitivity approximately $30 \mathrm{~km}$ downwind of the highest emissions.

[63] Acknowledgments. The authors would like to thank U. Facchini from the Milan University, B. Calpini from EPFL, and D. Ruffieux from the Swiss Meteorological Institute, who provided, respectively, the ${ }^{222} \mathrm{Rn}$, the
Lidar, and the wind profiler measurements. The authors would also like to thank G. Maffeis (Regione Lombardia) for providing the emission inventory. Partial support for S.S.'s participation was provided by the National Science Foundation (ATM-9713567).

\section{References}

Allegrini, I., A. Febo, A. Pasini, and S. Schiarini, Monitoring of the nocturnal mixed layer by means of particulate radon progeny measurements, J. Geophys. Res., 99, 765-777, 1994.

Bornstein, B. D., P. Thunis, P. Grossi, and G. Schayes, Development of the topographic vorticity mode mesoscale (TVM) model, II, Evaluation, J. Appl. Meteorol., 35, 1824-1834, 1996.

Brown, S. S., R. K. Talukdar, and A. R. Ravishankara, Rate constants for the reaction $\mathrm{OH}+\mathrm{NO}_{2}+\mathrm{M} \rightarrow \mathrm{HNO}_{3}+\mathrm{M}$ under atmospheric conditions, Chem. Phys. Lett., 299, 277-284, 1999.

Businger, J. A., J. C. Wyngaard, Y. Izumi, and E. F. Bradley, Flux-profile relationships in the atmospheric surface layer, J. Atmos. Sci., 28, 181189, 1971

Carter, W. P. L., Computer modeling of environmental chamber measurements of maximum incremental reactivities of volatile organic compounds, Atmos. Environ., 29, 2513-2527, 1995.

Chock, D. P., T. Y. Chang, S. L. Winkler, and B. I. Nance, The impact of an $8 \mathrm{~h}$ ozone air quality standard on ROG and $\mathrm{NO}_{x}$ controls in southern California, Atmos. Environ., 33, 2471-2486, 1999.

Clappier, A., A correction method for use in multidimensional time splitting advection algorithms: Application to two- and three- dimensional transport, Mon. Weather Rev., 126, 232-242, 1998.

Clappier, A., A. Martilli, P. Grossi, P. Thunis, F. Pasi, B. C. Krueger, B. Calpini, G. Graziani, and H. van den Bergh, Effect of sea breeze on air pollution in the greater Athens area, I, Numerical simulations and field observations, J. Appl. Meteorol., 39, 546-562, 2000.

Collella, P., and P. Woodward, The piecewise parabolic method (PPM) for gas dynamical simulations, J. Comput. Phys., 54, 174-201, 1984.

Davidson, A., Update on ozone trends in California's south coast air basin, J. Air Waste Manage. Assoc., 43, 226-227, 1993.

Derwent, R. G., M. E. Jenkin, and S. M. Saunders, Photochemical ozone creation potentials for a large number of reactive hydrocarbons under European conditions, Atmos. Environ., 30, 181-199, 1996.

Dickerson, R. R., S. Kondragunta, G. Stenchikov, K. L. Civerolo, B. G. Doddridge, and B. N. Holben, The impact of aerosols on solar ultraviolet radiation and photochemical smog, Science, 278, 827-830, 1997.

Dommen, J., A. S. H. Prévôt, B. Neininger, and M. Bäumle, Characterization of the photooxidant formation in the metropolitan area of Milan from aircraft measurements, J. Geophys. Res., 107, doi:10.1029/2000JD000283, in press, 2002

Finzi, G., C. Silibello, and M. Volta, Evaluation of urban pollution abatement strategies by a photochemical dispersion model, Int. J. Environ. Pollut., 14, 616-624, 2000

Giovannoni, J.-M., and A. G. Russell, Impact of using prognostic and objective wind fields on the photochemical modeling of Athens, Greece, Atmos. Environ., 29, 3633-3653, 1995.

Grell, G. A., S. Emeis, W. R. Stockwell, T. Schoenemeyer, R. Forkel, J. Michalakes, R. Knoche, and W. Seidl, Application of a multiscale, coupled MM5/chemistry model to the complex terrain of the VOTALP valley campaign, Atmos. Environ., 34, 1435-1453, 2000.

Grosjean, D., E. L. Williams II, and E. Grosjean, Peroxyacyl nitrates at southern California mountain forest locations, Environ. Sci. Technol., 27, 110-121, 1993a.

Grosjean, D., E. L. Williams II, and E. Grosjean, Ambient levels of peroxyn-butyryl nitrates at southern California mountain forest receptor locations, Environ. Sci. Technol., 27, 326-331, 1993 b.

Hall, B. D., and C. S. Claiborn, Measurements of the dry deposition of peroxides to a Canadian boreal forest, J. Geophys. Res., 102, 29,34329,353, 1997.

Harley, R. A., A. G. Russell, G. J. McRae, G. R. Cass, and J. H. Seinfeld, Photochemical modeling of the southern California air quality study, Environ. Sci. Technol., 27, 378-388, 1993.

Jacobson, M., Isolating nitrated and aromatic aerosols and nitrated aromatic gases as sources of ultraviolet light absorption, J. Geophys. Res., 104, 3527-3542, 1999.

Kleinman, L. I., Low and high-NO $\mathrm{NO}_{x}$ tropospheric photochemistry, J. Geophys. Res., 99, 16,831-16,838, 1994.

Kleinman, L. I., P. H. Daum, D. G. Imre, J. H. Lee, Y.-N. Lee, L. J. Nunnermacker, S. R. Springston, J. Weinstein-Lloyd, and L. Newman, Ozone production in the New York City urban plume, J. Geophys. Res., $105,14,495-14,511,2000$.

Lu, C. H., and J. S. Chang, On the indicator-based approach to assess ozone sensitivities and emissions features, J. Geophys. Res., 103, 3453-3462, 1998. 
Lurmann, F. W., W. P. Carter, and L. A. Coyner, A surrogate species chemical reaction mechanism for urban-scale air quality simulation models, I, Adaptation of the mechanism, Rep. 600/3-87/014A, Environ. Prot. Agency, Washington, D. C., 1987.

Maffeis, G., M. Longoni, A. De Martini, and M. Tamponi, Emissions estimate of ozone precursors during PIPAPO campaign, paper presented at Photochemical Oxidants and Aerosols in Lombardy Region, Milan, Italy, June 1999.

Meng, Z., D. Dabdub, and J. H. Seinfeld, Chemical coupling between atmospheric ozone and particulate matter, Science, 277, 116-119, 1997.

Milford, J., D. Gao, S. Sillman, P. Blossey, and A. G. Russell, Total reactive nitrogen $\left(\mathrm{NO}_{y}\right)$ as an indicator for the sensitivity of ozone to $\mathrm{NO}_{x}$ and hydrocarbons, J. Geophys. Res., 99, 3533-3542, 1994.

Pilinis, C., and J. H. Seinfeld, Continued development of a general equilibrium model for inorganic multicomponent atmospheric aerosols, Atmos. Environ., 21, 2453-2466, 1987.

Prévôt, A. S. H., J. Staehelin, G. L. Kok, R. D. Schillawski, B. Neininger, T. Staffelbach, A. Neftel, H. Wernli, and J. Dommen, The Milan photooxidant plume, J. Geophys. Res., 102, 23,375-23,388, 1997.

Ruggaber, A., Modeling radiation quantities and photolysis frequencies in the troposphere, J. Atmos. Chem., 18, 171-210, 1994.

Schayes, G. P., P. Thunis, and B. D. Bornstein, Development of the topographic vorticity mode mesoscale (TVM) model, I, Formulation, J. Appl. Meteorol., 35, 1815-1823, 1996.

Sesana, L., L. Barbieri, U. Facchini, and G. Marcazzan, ${ }^{222} \mathrm{Rn}$ as a tracer of atmospheric motions: A study in Milan, Radiat. Prot. Dosim., 78(1), 6571, 1998.

Silibello, C., G. Calori, G. Brusasca, G. Catenacci, and G. Finzi, Application of a photochemical grid model to Milan metropolitan area, Atmos. Environ., 32, 2025-2038, 1998.

Sillman, S., The use of $\mathrm{NO}_{y}, \mathrm{H}_{2} \mathrm{O}_{2}$ and $\mathrm{HNO}_{3}$ as indicators for $\mathrm{O}_{3}-\mathrm{NO}_{x}$ VOC sensitivity in urban locations, J. Geophys. Res., 100, 14,175$14,188,1995$

Sillman, S., The relation between ozone, $\mathrm{NO}_{x}$ and hydrocarbons in urban and polluted rural environments, Atmos. Environ., 33, 1821-1845, 1999.

Sillman, S., D. He, M. R. Pippin, P. H. Daum, D. G. Imre, L. I. Kleinman, J. H. Lee, and J. Weinstein-Lloyd, Model correlations for ozone, reactive nitrogen and peroxides for Nashville in comparison with measurements: Implications for VOC-NO ${ }_{x}$ sensitivity, J. Geophys. Res., 103, 22,62922,644, 1998

Simpson, D., A. Guenther, C. N. Hewitt, and R. Steinbrecher, Biogenic emissions in Europe, J. Geophys. Res., 100, 22,875-22,890, 1995.

Spirig, C., A. Neftel, J. Hjorth, and L. Kleinman, $\mathrm{NO}_{x}$ versus volatile organic compounds limitation of $\mathrm{O}_{3}$ production in the Po Valley: Loca and integrated view based on observations, J. Geophys. Res., 107, doi:10.1029/2001JD000561, in press, 2002

Staffelbach, T., et al., Photochemical oxidant formation over southern Swit- zerland, 1, Results from summer, 1994, J. Geophys. Res., 102, 23,34523,362, 1997a.

Staffelbach, T., A. Neftel, and L. W. Horowitz, Photochemical oxidant formation over southern Switzerland, 2, Model results, J. Geophys. Res., 102, 23,363-23,374, 1997b.

Stockwell, W. R., F. Kirchner, M. Kuhn, and S. Seefeld, A new mechanism for regional atmospheric chemistry modeling, J. Geophys. Res., 102, 25,847-25,879, 1997

Therry, G., and P. Lacarrère, Improving the eddy kinetic model for planetary boundary layer description, Boundary Layer Meteorol., 25, 63-88, 1983.

Thielmann, A., A. S. H. Prévôt, and J. Staehelin, Sensitivity of ozone production derived from field measurements in the Italian Po Basin, J. Geophys. Res., 107, doi:10.1029/2000JD000119, in press, 2002.

Thunis, P., and A. Clappier, Formulation and evaluation of a nonhydrostatic mesoscale vorticity model (TVM), Mon. Weather Rev., 128, 3236-3251, 2000 .

Tonnesen, G. S., and R. L. Dennis, Analysis of radical propagation efficiency to assess ozone sensitivity to hydrocarbons and $\mathrm{NO}_{x}, 1$, Local indicators of instantaneous odd oxygen production sensitivity, J. Geophys. Res., 105, 9213-9225, 2000a.

Tonnesen, G. S., and R. L. Dennis, Analysis of radical propagation efficiency to assess ozone sensitivity to hydrocarbons and $\mathrm{NO}_{x}, 2$, Longlived species as indicators of ozone concentration sensitivity, J. Geophys. Res., 105, 9227-9241, 2000b.

Wesely, M. L., and B. B. Hicks, Some factors that affect the deposition rates of sulfur dioxide and similar gases on vegetation, J. Air Pollut. Control Assoc., 27, 1110-1116, 1977.

Williams, E. L., II, and D. Grosjean, Peroxypropionyl nitrate at a southern California mountain forest site, Environ. Sci. Technol., 25, 653-659, 1991.

Williams, E. L., II, E. Grosjean, and D. Grosjean, Ambient levels of the peroxyacyl nitrates PAN, PPN and MPAN in Atlanta, Georgia, J. Air Waste Manage. Assoc., 43, 873-879, 1993

Young, T. R., and J. P. Boris, A numerical technique for solving stiff ordinary differential equations associated with the chemical kinetics of reactive flows problems, J. Phys. Chem., 81, 2424-2427, 1977.

A. Clappier, F. Kirchner, and A. Martilli, Laboratoire de Pollution de l'Air et des Sols, Ecole Polytechnique Federale Lausanne, CH-1015 Lausanne, Switzerland. (alain.clappier@epfl.ch)

G. Favaro, Swiss Meteorological Institute, Station Aérologique de Payerne, Payerne, Switzerland.

A. Neftel, Institut für Umwelt und Landwirtschaft, CH-3003 Bern, Liebefeld, Switzerland.

S. Sillman, Department of Atmospheric, Oceanic and Space Sciences, University of Michigan, Ann Arbor, MI 48109-2143, USA. 
a)
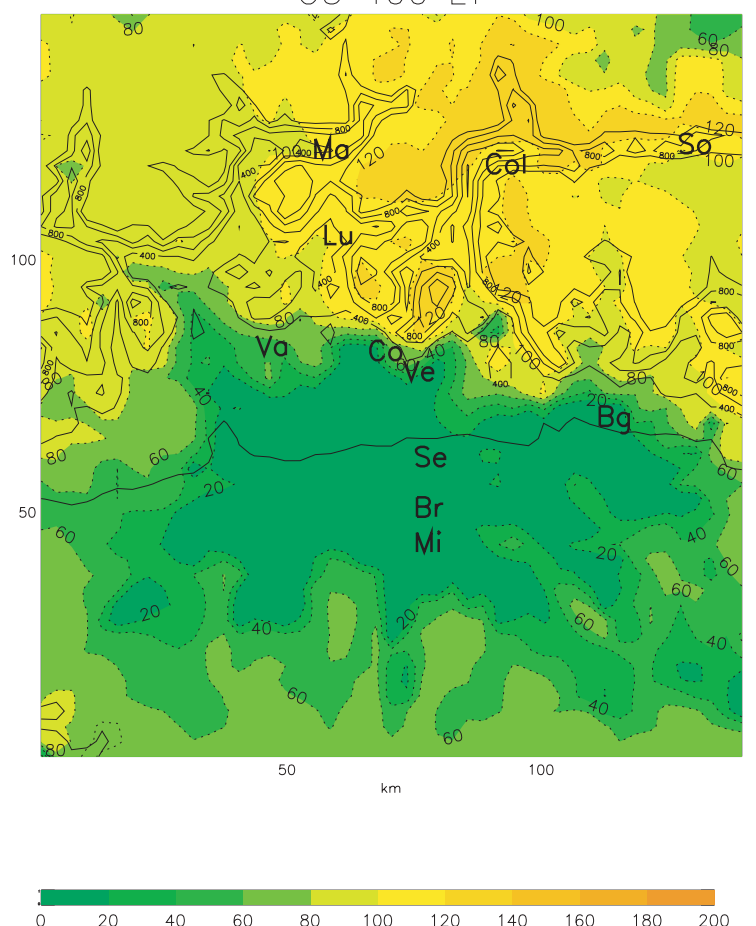

$\mathrm{ppb}$

c)
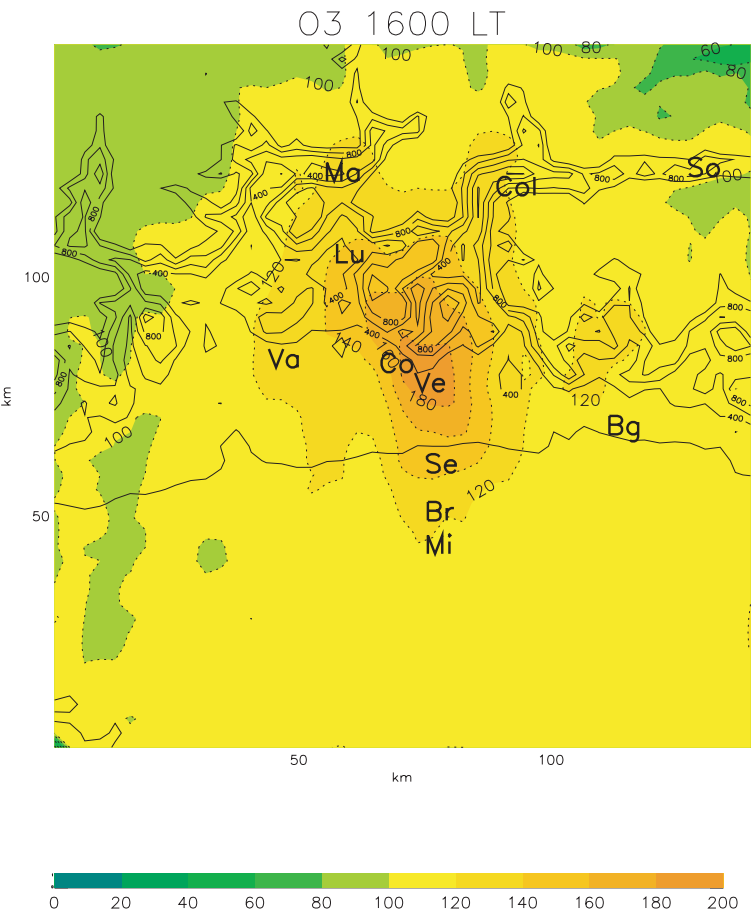

$\mathrm{ppt}$

Figure 8. Simulated $\mathrm{O}_{3}$ values within the first vertical layer (30 m) at (a) $0400 \mathrm{LT}$, (b) $1200 \mathrm{LT}$, and (c) 1600 LT. 

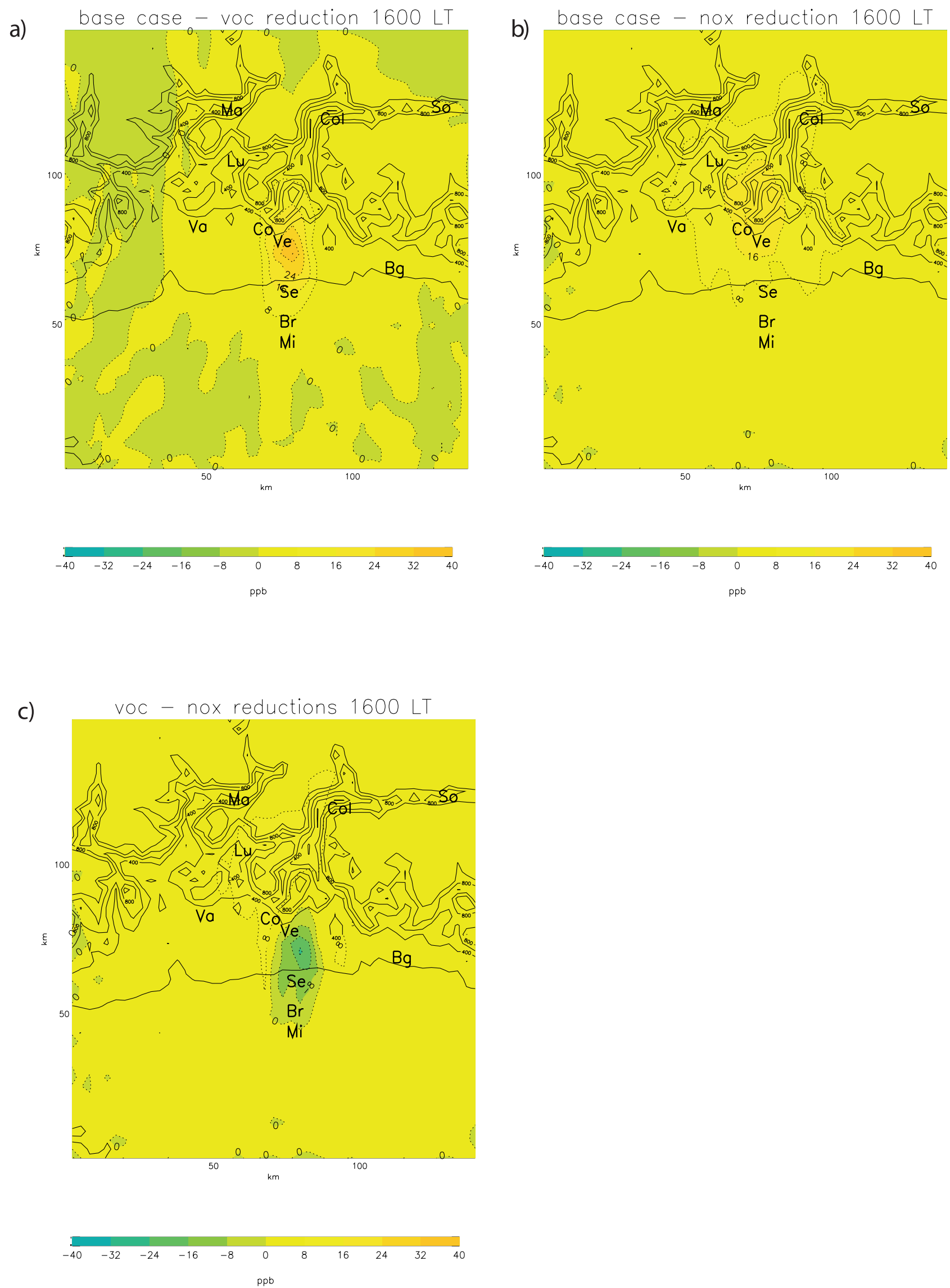
Figure 10. (opposite) Predicted change in surface $\mathrm{O}_{3}(\mathrm{ppb})$ at 1600 LT resulting from a 35\% reduction in anthropogenic VOC emissions (Figure 10a) and from a 35\% reduction in $\mathrm{NO}_{x}$ emissions (Figure 10b). Figure 10c shows the difference between the reduced-VOC and reduced- $\mathrm{NO}_{x}$ runs, with positive values corresponding to locations with lower $\mathrm{O}_{3}$ in the run with reduced $\mathrm{NO}_{x}$. Results are from simulations that include aerosols. 